\title{
DERIVATIVE IDEAS AND THE VALUE OF INTANGIBLE ASSETS*
}

\author{
By John Laitner And Dmitriy Stolyarov ${ }^{1}$
}

University of Michigan, U.S.A.

\begin{abstract}
We build a general equilibrium model where growth is driven by two invention types: fundamental ideas that cause creative destruction, and derivative ideas that enhance the value of existing inventions. The model provides a new mapping from microeconomic, patent data to aggregate total factor productivity growth and the aggregate value of privately owned knowledge. We show how to measure the frequency of derivative ideas and the rate of creative destruction. We estimate that derivative ideas account for $70-80 \%$ of all patents and their presence more than doubles the value of knowledge capital relative to what the measured innovation rate might otherwise imply.
\end{abstract}

\section{INTRODUCTION}

The goal of this article is to study the aggregate value of private knowledge. Intangible capital in the form of privately owned knowledge is a potentially sizable component of the stock of business assets, and its interrelationship with technological progress seems both extensive and interesting. Observations of the market value of businesses do not directly determine the value of knowledge, as intangible capital may have other components (Corrado et al., 2006). Our analysis uses a model-based, indirect approach to connect the aggregate value of knowledge capital with microeconomic data on patent citations. We start with a general equilibrium quality ladder model in which one can decompose aggregate total factor productivity (TFP) growth, and the depreciation of knowledge capital, into underlying components. Then, we develop a mapping between these components and patent citation behavior. Finally, using patent data, we calibrate the model and derive new measurements of the economy's stock of knowledge capital, components of its depreciation rate, and constituent parts of the process for aggregative TFP growth.

Our formulation extends a standard quality ladder model to include two types of inventions, which we call fundamental and derivative. A fundamental idea replaces earlier innovations in its sector and causes creative destruction. A derivative idea builds on the latest existing innovation and may augment its value. In contrast to standard treatments, our model makes innovation and creative destruction separate events, which occur at different rates.

In our framework, patent citations arise because derivative ideas acknowledge their dependence on previous innovations. We assume that a citation "delimits the scope of the property rights awarded by a patent" (Trajtenberg et al., 2002, p. 53). ${ }^{2}$ Then, all derivative patents should

\footnotetext{
*Manuscript received May 2010; revised January 2012.

${ }^{1}$ The authors wish to thank the editor and referees for many valuable suggestions and comments and the participants of various seminars for their feedback. Stolyarov gratefully acknowledges the financial support from the National Science Foundation (NSF) SES-0241640. Please address correspondence to: Dmitriy Stolyarov, Department of Economics, University of Michigan, 611 Tappan Ave., 238 Lorch, Ann Arbor, MI 48109-1220. Phone: 734-647-5609; Fax: 734-764-2769. E-mail: stolyar@umich.edu.

${ }^{2}$ A great deal of evidence supports the idea that when one patent cites another, the corresponding inventions are complementary and that citations attempt to acknowledge the degree of overlap. Harhoff et al. (1999) show that European patents are more likely to be renewed if they are frequently cited, and patent values, as directly assessed by their owners, are higher for patents receiving more citations; Lanjouw and Schankerman (2004) find that the mean value of the quality of a firm's patent portfolio, measured in part with citations received, positively affects stock market valuations in most cases; and Jaffe et al. (2002) report positive knowledge spillovers from cited patents. Hall et al.
} 


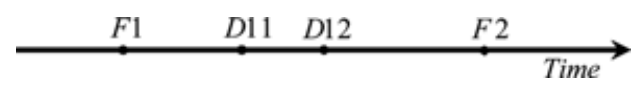

FIGURE 1

HYPOTHETICAL STREAM OF INNOVATIONS FOR AN INDUSTRY

make at least one citation. We take "property rights" to mean that existing, active patents have blocking power over derivatives that cite them. This affects the value of derivative patents and prevents them from causing creative destruction.

In practice, patents originate at a high overall rate in the economy. A quality ladder model interprets the total flow as composed of numerous, separate streams, one for each "industry." Figure 1 illustrates a hypothetical stream of innovations in an industry on a time axis and labels each as either fundamental or derivative. In Figure 1, $F 1$ is a fundamental patent. $D 11$ is a derivative of $F 1$, and it cites $F 1$. D12 is the second derivative of $F 1$, and it cites both $F 1$ and $D 11 . F 2$ is the next fundamental idea. When it appears, the values of $F 1, D 11$, and $D 12$ are destroyed, and citations to them cease. ${ }^{3}$

Our model has Poisson arrival rate $\lambda$ for inventions within each industry, and it assumes that a fraction $\theta$ of inventions are derivative. In Figure 1, any derivative cites its immediate predecessor. We then calibrate $\lambda$ from data on the minimum citation lags for derivative patents. We estimate a 5-6 year average spacing for same-stream inventions. Similarly, the oldest citation that a derivative patent makes is its parent fundamental idea. Accordingly, we use data on maximum citation lags to calculate $\theta$. We estimate $\theta=0.7-0.8$. Section 4 provides details. Given values for $(\lambda, \theta)$, Section 5 shows that we can calibrate remaining parameters of our model from more conventional data sources.

If each new invention caused creative destruction, the average economic life span of patents, $1 / \lambda$, would be 5-6 years. If, however, a fraction $\theta$ of patents cover derivative ideas, we show that the average life span is extended to $1 /[\lambda \cdot(1-\theta)]$ and the corresponding rate of creative destruction equals $\lambda \cdot(1-\theta)$. In our calibrations, this more than doubles the capitalized value of intangible capital. We refer to the increase as the "longevity effect" stemming from society's recognition of existing property rights.

Because we assume that citations give senior patents blocking power over new derivatives, senior patents can, in principle, appropriate rents from derivative ideas. Our model captures blocking with profit allocation rules among fundamental and derivative patents that depend on a "blocking effect" parameter $b \in[0,1]$. If senior patents do not exercise blocking power (which leaves only the "longevity effect"), $b=0$. In this case, the owner of a derivative idea keeps the full increment of rent that his/her invention creates. At the other extreme, senior patents exercise their maximal blocking power and $b=1$. In that case, a fundamental idea usurps all rents from subsequent derivative inventions (until the next fundamental idea arrives and causes creative destruction). Section 5 shows that we can calibrate $b$ from knowledge depreciation rates in the literature. We find $b \in[0,0.1]$ so that the "blocking effect" produces only a small additional increase in the aggregate value of intangible capital. ${ }^{4}$

(2005, p. 18) write: "Thus, if patent B cites patent A, it implies that patent A represents a piece of previously existing knowledge upon which patent B builds, and over which B cannot have a claim.” See also Jaffe et al. (1993, p. 580) and Section 4 below.

${ }^{3}$ A concrete example is as follows: In September 1973, Texas Instruments obtained one of the early patents on a single-chip microprocessor design (U.S. patent 3757306). In February 1976, Xerox patented a new input-output connection for elements of the microprocessor (U.S. patent 3938098) and cited the original Texas Instrument patent. In April 1978, Motorola patented an interrupt system for controlling communication between microprocessor parts (U.S. patent 4086627) and cited both previous patents. Think of the microprocessor design as a "fundamental" idea, followed by "derivative" improvements.

${ }^{4}$ The value of $b$ is potentially of independent interest in the microeconomics literature, where rent allocations may determine incentives to invent (e.g., Scotchmer, 1991, 1996; Chang, 1995; Green and Scotchmer, 1995; Matutes et al., 1996; and others). 
Taking into account longevity and blocking effects, our model predicts an aggregate value of privately owned knowledge of about 25 cents per dollar of physical capital. Recent studies provide valuations of intangible capital that include categories in addition to knowledge (see Section 5). Existing estimates tend to fall within the range of 50-70 cents per dollar of physical capital (e.g., McGrattan and Prescott, 2000; Hall et al., 2001; Laitner and Stolyarov 2003). ${ }^{5}$ Our results then indicate that privately owned knowledge accounts for at least one-third of the total stock of intangible capital.

Our framework can enhance our understanding of the depreciation rate for knowledge and of its components. Standard analyses associate depreciation of knowledge with creative destruction, yet available estimates of the depreciation rate on patents $(15 \%$ is the literature consensus cited by Hall et al., 2005) far exceed the estimated rate of creative destruction $(3.5 \%$ annually in Caballero and Jaffe, 2002). Our general equilibrium framework provides an interpretation. We show that a sector whose TFP is stagnating loses market share as innovations in other sectors make the prices of competing goods fall and wages rise. Active patents in the stagnating sector then depreciate from "obsolescence." In our calibrations, obsolescence accounts for $80 \%$ of knowledge depreciation, whereas creative destruction contributes only $20 \%$.

General equilibrium implications of our analysis extend beyond the value of intangible capital. We can calibrate our model without using direct information on markups. We find that our calibrations point to modest markups, which seem consistent with several recent estimates from the literature. In our model, modest markups imply a small quality ladder step size. The model has limit pricing, with markups that vary over time and across industries. Cross-sectional markup asymmetry causes input misallocation that reduces the aggregate TFP level. However, according to our calibrations, the resulting TFP loss is quantitatively small.

Our model also sheds light on a dynamic factor affecting aggregate TFP growth. In a quality ladder formulation, the overall rate of technological progress reflects the product of the rate of innovation and the average quality step size. Despite the fast rate of innovation noted above, a small step size makes average industry TFP growth rather slow, about $1 \%$ annually. However, a dynamic input reallocation effect emerges. Our model has many industries, each with its own Poisson process for TFP growth. Over time some industries surge ahead of others. Market incentives cause physical capital and labor to flow to sectors with the highest TFP. This raises the market share of TFP leaders, accenting their role in the overall economy. In our calibrations, aggregate TFP growth is $50 \%$ faster than average TFP growth in the economy's separate industries.

It is natural to ask if the nature of technological change might have changed in recent decades. Our analysis does suggest that the number of derivative patents may have risen. The root cause could have been a shift in technological change toward sectors with inherently high spillovers, such as semiconductors and computer hardware and software (Bessen and Maskin, 2006). Or, it could have been a change in patent policy to one affording protection to previously unpatentable areas or allowing more overlap in property rights (e.g., Hunt, 2001; Jaffe and Lerner, 2004). Our complete set of estimates implies, however, that a nearly coincident increase in the overall rate of patenting tended, in practice, to offset the rise in derivatives in terms of the overall value of knowledge capital.

Our analysis can complement the study of endogenous growth. The endogenous growth literature focuses on understanding the relationship between inputs and outputs in the production of R\&D and between R\&D output and productivity growth. For example, Kortum $(1993,1997)$ investigates, theoretically and empirically, the time path of average patent output per researcher and its consistency with aggregate TFP growth. Caballero and Jaffe (2002) use data on patent citations and the market value of firms to estimate the rate of creative destruction and the rate of diffusion of knowledge among innovators. ${ }^{6}$ This article measures innovation directly from

\footnotetext{
${ }^{5}$ See also Corrado et al. (2006) and McGrattan and Prescott (2005).

${ }^{6}$ See also Ngai and Samaniego (2009), who develop a multisector model to account for industry differences in TFP growth, R\&D intensity, and knowledge spillovers. They distinguish between industry-level and firm-level spillovers
} 
patent data-devoting its attention to studying the nature of innovation and the connection between innovation, on the one hand, and intangible capital and economy-wide TFP growth, on the other. Even if our goal was to determine incentives for R\&D, we would need to understand the market value of inventions.

A number of the seminal endogenous growth models assumed that knowledge from the past entered current production purely as an externality (e.g., Grossman and Helpman, 1991; Segerstrom, 1991; Kortum, 1997; Caballero and Jaffe, 2002). Our analysis assumes that a fraction of new inventions are derivative instead of fundamental; that a derivative invention does not destroy the economic value of its parent fundamental idea, and may, in fact, increase it; and that patent citation rules provide prima facie evidence that society requires new patents to recognize the ownership rights of previous inventions, at least to a degree.

Empirical papers have noted the heterogeneity of patent values, with recent work revealing a positive correlation between a citations and valuations-e.g., Hall et al. (2005), Belenzon (2006), Bertrand (2006), and Cai (2009). The first reference suggests that the nature of the empirical correlation is complex, with future, instead of past, citations apparently playing by far the dominant role. Section 5 explores the consistency of our analysis with the latter findings.

The organization of this article is as follows: Section 2 presents our basic model. We show that we can derive an aggregate production function and simple description of balanced-growth equilibrium. Section 3 focuses on the valuation of intangible capital arising from appropriable knowledge. Section 4 turns to U.S. patent data, using citation lags to estimate $\lambda$ and $\theta$. Section 5 calibrates the complete model and presents results. Section 6 concludes.

\section{MODEL AND EQUILIBRIUM}

This section sets up our model of the economy. Assuming an exogenously growing and inelastic supply of labor, an exogenous flow of new inventions, and a representative agent model of saving and consumption, we develop an aggregate production function and characterize a balanced-growth equilibrium.

2.1. Production. The single final good (whose price is normalized to unity) is produced from a continuum of differentiated intermediate inputs supplied by industries indexed by $j \in$ $[0,1] .{ }^{7}$ If $x_{j t}$ is the quantity of intermediate good $j$ and $Y_{t}$ is aggregate output of the final good, we have

$$
Y_{t}=\left(\int_{0}^{1} x_{j t}^{\eta} d j\right)^{\frac{1}{\eta}}, \quad \eta \in(0,1) .
$$

Let $p_{j t}$ be the price of intermediate good $j$. Total profit in the final-good sector is

$$
\left(\int_{0}^{1}\left[x_{j t}\right]^{\eta} d j\right)^{1 / \eta}-\int_{0}^{1} p_{j t} \cdot x_{j t} d j .
$$

Final-good sector profit maximization determines the demand for intermediate good $j$ :

$$
\left(\frac{Y_{t}}{x_{j t}}\right)^{1-\eta}=p_{j t}
$$

and associate the latter with the fraction of self-citations in the firm's patent portfolio. In their model, the depreciation rate on knowledge is assumed to be a parameter unaffected by spillovers.

${ }^{7}$ See also Barro and Sala-i-Martin (1999, ch. 7) for a quality ladder model with constant elasticity of substitution between intermediate inputs. 
Intermediate-good industry $j$ uses a Cobb-Douglas production technology with capital $K_{j t}$ and labor $L_{j t}$ as inputs:

$$
x_{j t}=Z_{j t} K_{j t}^{\alpha} L_{j t}^{1-\alpha}, \alpha \in(0,1)
$$

where $Z_{j t}$ is the TFP level corresponding to the currently active production technology in the industry. Physical capital and labor are not industry-specific, so, all intermediate-good firms face common factor prices for capital and labor. We denote the factor prices as $R_{t}$ and $W_{t}$, respectively. The corresponding marginal cost of operating technology $Z_{j t}$ at time $t$ is

$$
c_{j t}=\frac{1}{Z_{j t}}\left(\frac{R_{t}}{\alpha}\right)^{\alpha}\left(\frac{W_{t}}{1-\alpha}\right)^{1-\alpha}=\frac{c_{t}}{Z_{j t}} .
$$

2.2. Industry TFP. Technological progress in an industry comes from periodic innovations that increase the TFP level. Think of innovations as arising outside of the intermediate-goods sector-e.g., households exogenously discover new ideas (through luck or inspiration), appropriate them with patents, and sell the patents to intermediate-goods firms. ${ }^{8}$ Assume that the maximum TFP level in industry $j$ is a jump process governed by an industry-specific Poisson random variable with an exogenous arrival rate $\lambda$. Each Poisson event in industry $j$ raises the maximum TFP level in the industry by a factor of $z>1$. Let $N_{j t}$ be the cumulative number of technological innovations (Poisson events) in industry $j$ by time $t$. Innovation $n \leq N_{j t}$ delivers TFP level $z^{n}$. The Poisson processes have the same parameters in all industries, but they operate independently of one another; consequently, the model features a time-varying cross-sectional distribution of TFP levels across industries.

To highlight key new features of the framework and explain how they relate to the original quality ladder model, we next turn to a detailed description of industry behavior.

2.3. Derivative ideas. The original quality ladder model assumes that each innovation is a stand-alone production technology. That is, in order to produce intermediate good $j$ from capital and labor using technology $z^{n}$, a firm only need license the patent for innovation $n$. In contrast, our model allows production to depend on multiple inventions. In other words, an industry will often have multiple active patents.

For any intermediate-good industry $j$, a Poisson process generates innovations at rate $\lambda$. Suppose innovations can be of two types: with probability $1-\theta$, the innovation is a fundamental idea that initiates a new stand-alone technology; with probability $\theta$, it is a derivative idea that improves the efficiency of the current technology in its industry. Put differently, a fundamental idea brings a new approach, breaking with the past and rendering existing patents obsolete, whereas a derivative idea enhances the usefulness of the currently active fundamental idea. The rate of creative destruction in our model equals the rate of arrival of new fundamental ideas $\lambda(1-\theta)$. (The original quality ladder model has $\theta=0$.)

Let $N_{j t}=F_{j t}+D_{j t}$, where $F_{j t} \leq N_{j t}$ is the index of the most recent fundamental idea and $D_{j t} \geq 0$ is the number of derivative ideas that have arrived since. In order to operate a technology with TFP level $z^{F_{j t}+d}$, a firm must license a total of $d+1$ patents-representing the "parent" fundamental idea and all intervening derivatives. We assume that a fundamental idea and its derivatives operate together in a "patent pool." Although it is possible to form patent pools from the fundamental idea and $d<D_{j t}$ derivatives, including all the $D_{j t}$ derivatives maximizes the pool's surplus. The equilibrium size of the currently active patent pool is therefore $D_{j t}+1$.

\footnotetext{
${ }^{8}$ Our theoretical model uses the terms "innovation," "new idea," and "invention" interchangeably-assuming that new ideas can be embodied in inventions, making them patentable. Although, in practice, not all inventors rely on patents (e.g., Levin et al., 1987), our model assumes a one-to-one relationship between inventions and patents, with the latter serving as a metaphor for ownership. Section 4 discusses our empirical treatment. Also, note that patents in this article have no exogenous expiration date-rather, as explained below, patents endogenously become obsolete.
} 
As in the standard quality ladder model, we assume that each fundamental idea has a separate owner. Antitrust laws have no reason to tolerate monopolistic acquisition of multiple, sequential fundamental patents. Derivative ideas are a different matter. In fact, our model assumes that patent law protects the primacy of senior ideas that "applications" utilize.

Because the average number of ideas required to operate the frontier technology depends positively on $\theta$, we can interpret the latter as measuring the average degree of complementarity between innovations. We can also interpret $\theta$ as measuring the extent of compensated knowledge spillovers from fundamental ideas-the higher the value of $\theta$, the higher is the average number of derivative innovations per fundamental patent.

2.4. Industry equilibrium. We assume that patent pools in an industry engage in Bertrand price competition. At any time, several pools can produce the same intermediate good using technologies with different marginal costs. The industry leader-the pool with TFP level $z^{N_{j t}}$ has the lowest marginal cost; hence, under Bertrand competition, the leader produces all output of the given intermediate good. Given industry demand (2), profit maximization implies that the leader charges the unconstrained monopoly price $p_{j t}=(1 / \eta) \cdot\left(c_{t} / z^{N_{j t}}\right)$ if it exists and is below the closest rival's marginal cost; otherwise, the leader charges a limit price equal to the closest rival's marginal cost. As stated, each patent pool consists of a fundamental patent and all of its derivative patents. The leader's closest rival is the patent pool whose technology is based on the previous fundamental idea (and all its derivatives) and has TFP level $z^{N_{j t}-D_{j t}-1}$. The equilibrium price of good $j$ thus equals

$$
p_{j t}=\min \left\{\frac{c_{t}}{z^{F_{j t}-1}}, \frac{1}{\eta} \frac{c_{t}}{z^{N_{j t}}},\right\}=m_{j t} \cdot \frac{c_{t}}{z^{N_{j t}}},
$$

where the industry markup is

$$
m_{j t}=\min \left\{z^{D_{j t}+1}, \frac{1}{\eta}\right\}
$$

2.5. Industry markups. In the case of limit pricing, an intermediate-good industry's markup rises with the number of derivative improvements $D_{j t}$, because improvements decrease the leader's marginal cost while leaving the rival's marginal cost unchanged. When $D_{j t}$ becomes sufficiently large, the markup reaches its highest value, $1 / \eta$, and stays there until the next fundamental idea arrives. Upon a fundamental innovation's arrival, $D_{j t}$ resets to zero. If $\eta$ is close to 1 , intermediate goods are close substitutes for one another, so demand for good $j$ is price elastic, making the leader naturally reticent to raise its price too far. Then, unconstrained monopoly pricing will tend to obtain in (5). If $\eta$ is low, intermediate goods are poor substitutes for one another, the demand curve for each is correspondingly price inelastic, and the leader's impetus to raise its price is powerful. Then, marginal cost of the closest rival is likely to be a binding limitation. For $z>1 / \eta$, limit pricing never obtains in (5), and $m_{j t}$ is constant and equal to the unconstrained monopoly markup $1 / \eta$. Otherwise, the industry markup is a jump process with a set of $H$ states

$$
\vec{m}=\left(z, z^{2}, \ldots z^{H-1}, 1 / \eta\right)^{T}
$$

Depending on the current size of its patent pool, the industry will be in one of the $H$ states, $h$, with markup $m_{h}$. 
Transitions between states occur at times when innovations arrive. An $H \times H$ matrix

$$
\mathbf{M}=\left(\begin{array}{ccccc}
1-\theta & \theta & 0 & \ldots & 0 \\
1-\theta & 0 & \theta & \ldots & 0 \\
\ldots & \ldots & \ldots & \ldots & \ldots \\
1-\theta & 0 & \ldots & 0 & \theta \\
1-\theta & 0 & \ldots & 0 & \theta
\end{array}\right)
$$

governs the transitions. From any state $1 \leq h<H$, an industry transits to pool size $h+1$, and markup $m_{h+1}$, with probability $\theta$, but it returns to pool size 1 , and markup state $m_{1}$, with probability $1-\theta$. Matrix $\mathbf{M}$ has a unique stationary distribution, i.e., the row vector

$$
\overrightarrow{\boldsymbol{a}}_{*}=\left[1-\theta,(1-\theta) \theta, \ldots(1-\theta) \theta^{H-2}, \theta^{H-1}\right] \in R^{H},
$$

for which

$$
\vec{a}_{*} \cdot \mathbf{M}=\vec{a}_{*}, \quad \vec{a}_{*} \geq 0, \quad \sum_{h=1}^{H} a_{* h}=1 .
$$

For each $h<H$, the element $a_{* h}$ equals the long-run probability that a randomly selected industry has $h-1$ derivative ideas and markup $m_{h}$. The last element of $\vec{a}_{*}$ is the probability that an industry has $H-1$ or more derivative ideas, hence markup $1 / \eta$.

2.6. Aggregation. We want to characterize the time path for the equilibrium of the aggregate economy. Let the initial distribution, by industry, of markup states and TFP levels $\left(m_{j 0}, Z_{j 0}\right), j \in[0,1]$, be given. Let $N_{j t}$ now stand for the number of Poisson events in industry $j$ after time 0 so that

$$
Z_{j t}=Z_{j 0} \cdot z^{N_{j t}}
$$

We can define the partial equilibrium for the production side of the economy as follows: Let the time paths for factor prices $R_{t}$ and $W_{t}$ and their aggregate quantities $K_{t}$ and $L_{t}$ be given. Then, we have the following definition.

Definition 1. A production-side (partial) equilibrium is a time path

$$
\left\{R_{t}, W_{t}, K_{t}, L_{t}, Y_{t}, x_{j t}, K_{j t}, L_{j t}, N_{j t}, p_{j t}\right\}, \quad t \geq 0,
$$

consistent with initial conditions and

(i) profit maximization in the final-good sector, with final-good producers taking $p_{j t}$ as given,

(ii) profit maximization with Bertrand price competition in each intermediate industry, with producers taking $R_{t}$ and $W_{t}$ as given,

(iii) production functions as in Equations (1) and (3),

(iv) full employment of capital

$$
\int_{0}^{1} K_{j t} d j=K_{t} \quad \text { all } \quad t \geq 0
$$

(v) labor market clearing

$$
\int_{0}^{1} L_{j t} d j=L_{t} \quad \text { all } \quad t \geq 0 .
$$


We can show that an economy in a production-side equilibrium has an aggregate production function.

Lemma 1. Suppose that at time t, the economy is in a production side equilibrium. Then, the economy has an aggregate production function

$$
Y_{t}=Z_{t} K_{t}^{\alpha} L_{t}^{1-\alpha}
$$

where

$$
Z_{t}=\frac{\left(\int_{0}^{1}\left[Z_{j t}\right]^{\frac{\eta}{1-\eta}}\left[m_{j t}\right]^{-\frac{\eta}{1-\eta}} d j\right)^{1 / \eta}}{\int_{0}^{1}\left[Z_{j t}\right]^{\frac{\eta}{1-\eta}}\left[m_{j t}\right]^{-\frac{1}{1-\eta}} d j} .
$$

The division of national income between physical capital, labor, and monopoly profits is

$$
R_{t} K_{t}=\frac{\alpha}{m_{t}} Y_{t}, \quad W_{t} L_{t}=\frac{1-\alpha}{m_{t}} Y_{t}, \quad \Pi_{t}=\frac{m_{t}-1}{m_{t}} Y_{t}
$$

where

$$
m_{t}=\frac{\int_{0}^{1}\left[Z_{j t}\right]^{\frac{\eta}{1-\eta}}\left[m_{j t}\right]^{-\frac{\eta}{1-\eta}} d j}{\int_{0}^{1}\left[Z_{j t}\right]^{\frac{\eta}{1-\eta}}\left[m_{j t}\right]^{-\frac{1}{1-\eta}} d j}
$$

Proof. See the Appendix.

Note that $Z_{t}$ and $m_{t}$ are deterministic, since they depend only on the expected values of functions of random variables $Z_{j t}$ and $m_{j t}$. The standard rental fee formula determines the interest rate

$$
r_{t}=R_{t}-\delta=\frac{\alpha}{m_{t}} \cdot \frac{Y_{t}}{K_{t}}-\delta
$$

where $\delta$ is the rate of depreciation on physical capital.

If our independent Poisson processes govern the arrival of new ideas across industries for many years leading up to time 0 , we expect to observe the stationary distribution of markups at time 0 -i.e., the fraction of intermediate-good industries with markup $m_{h}$ should be $a_{* h}$. Innovations within industry $j$ cause the markup $m_{j t}$ endlessly to cycle through states $m_{1}$ to $m_{H}$. In contrast, $Z_{j t}$ rises monotonically. After the passage of time, there is no reason to expect a relationship between $m_{j t}$ and $Z_{j t}$. In this light, we assume that the economy starts with the initial condition that corresponds to the stationary distribution of markups.

Initial Condition IC. At $t=0$, the (given) distribution of markups $m_{j 0}, j \in[0,1]$, induces, in aggregate, the stationary distribution of markup states $\vec{a}_{*}$, and the (given) distribution of TFP levels, $Z_{j 0}, j \in[0,1]$, is independent of the distribution of markups. We assume that the mean $\mathbb{E}\left[Z_{j 0}^{\frac{\eta}{1-\eta}}\right]$ is finite.

As shown below, with this initial condition, the aggregate equations of motion for the economy are time autonomous and similar to those of the standard Ramsey model. 
Let $\vec{m}^{x}$ denote an $H \times 1$ vector consisting of the elements of vector $\vec{m}$ raised to the power $x$. We have

Corollary to Lemma 1. Let $Z_{t}$ be as in (7), $m_{t}$ be as in (9), and let initial condition IC hold. Then, for all $t \geq 0$,

$$
m_{t}=m_{*}=\frac{\vec{a}_{*} \cdot \vec{m}^{-\frac{\eta}{1-\eta}}}{\vec{a}_{*} \cdot \vec{m}^{-\frac{1}{1-\eta}}}
$$

$$
Z_{t}=\bar{Z}_{0} \cdot \bar{m} \cdot \exp \left(\gamma \frac{1-\eta}{\eta} t\right)
$$

where

$$
\bar{Z}_{0} \equiv\left(\mathbb{E}\left[Z_{j 0}^{\frac{\eta}{1-\eta}}\right]\right)^{\frac{1-\eta}{\eta}}, \quad \bar{m} \equiv \frac{\left(\vec{a}_{*} \cdot \vec{m}^{-\frac{\eta}{1-\eta}}\right)^{\frac{1}{\eta}}}{\vec{a}_{*} \cdot \vec{m}^{-\frac{1}{1-\eta}}}, \gamma=\lambda\left(z^{\frac{\eta}{1-\eta}}-1\right)
$$

Proof. See the Appendix.

By Jensen's inequality, $\bar{m} \leq 1$. It measures the extent of resource misallocation caused by markups that are asymmetric across industries. (If $\theta=0$ or $z>\frac{1}{\eta}$, then markups are equal across industries and $\bar{m}=1$.)

2.7. Households. The representative household consists of

$$
L_{t}=L_{0} e^{n t}, n \geq 0
$$

members, it inelastically supplies $L_{t}$ units of labor, and it maximizes

$$
\int_{0}^{\infty} e^{-\rho t} L_{t} \cdot \frac{\left(C_{t} / L_{t}\right)^{1-\sigma}}{1-\sigma} d t, \sigma>1
$$

subject to its lifetime budget constraint.

As stated, members of the representative household exogenously discover new ideas, patent them, and sell them to intermediate-good firms. Although each industry $j$ receives new ideas at random times, there is no aggregate uncertainty about the value of new patents or income derived from patents. Since the representative household expects to appropriate all future ideas, it owns the entire stream of future monopoly profits. Consequently, household lifetime resources consist of physical capital stock $K_{t}$, the present value of labor earnings, and capitalized monopoly profits. The household time $t$ budget constraint is

$$
\int_{t}^{\infty} e^{-\bar{r}(t, s)} C_{s} d s=K_{t}+\int_{t}^{\infty} e^{-\bar{r}(t, s)}\left(\Pi_{s}+W_{s} L_{s}\right) d s
$$

where

$$
\bar{r}(t, s)=\int_{t}^{s} r_{x} d x
$$

The differential form of the lifetime budget constraint gives the law of motion for capital stock:

$$
\dot{K}_{t}=r_{t} K_{t}+\Pi_{t}+W_{t} L_{t}-C_{t} \Longleftrightarrow \dot{K}_{t}=Y_{t}-C_{t}-d K_{t} .
$$


2.8. General equilibrium. Define a general equilibrium for our model as follows:

Definition 2. A general equilibrium is a time path

$$
\left\{R_{t}, W_{t}, K_{t}, L_{t}, Y_{t}, x_{j t}, K_{j t}, L_{j t}, N_{j t}, p_{j t}, r_{t}, \Pi_{t}, C_{t}\right\}, \quad t \geq 0,
$$

with $\left\{R_{t}, W_{t}, K_{t}, L_{t}, Y_{t}, x_{j t}, K_{j t}, L_{j t}, N_{j t}, p_{j t}\right\}$ constituting a production-side equilibrium, $r_{t}$ satisfying (10), $\Pi_{t}$ satisfying (8), and $C_{t}$ consistent with constrained maximization on the part of the representative household.

Solving the optimal consumption problem for the household yields the familiar Euler equation

$$
\frac{\dot{C}_{t}}{C_{t}}=n+\frac{1}{\sigma}\left(r_{t}-\rho\right) .
$$

Differential equations (14)-(15) together with aggregate production function (6) and formula (10) determine the aggregate dynamics of the model. When the economy has initial condition IC, we can make these equations time-autonomous. Changing variables to

$$
k_{t} \equiv \frac{K_{t}}{Z_{t^{\frac{1}{1-\alpha}}} L_{t}}, \quad c_{t} \equiv \frac{C_{t}}{Z_{t^{\frac{1}{1-\alpha}}} L_{t}}, \quad y_{t} \equiv \frac{Y_{t}}{Z_{t}^{\frac{1}{1-\alpha}} L_{t}}=k_{t}^{\alpha},
$$

and letting

$$
g=\frac{1}{1-\alpha} \frac{1-\eta}{\eta} \gamma
$$

(14)-(15) yield

$$
\begin{aligned}
& \dot{k}_{t}=k_{t}^{\alpha}-(n+\delta+g) k_{t}-c_{t}, \\
& \frac{\dot{c}}{c}=\frac{1}{\sigma}\left(\frac{\alpha}{m_{*}} k_{t}^{\alpha-1}-\delta-\rho\right)-g .
\end{aligned}
$$

These are virtually the same equations of motion as in the Ramsey model. Thus, our analysis maintains consistency with standard aggregate equations, even though it is built from different microfoundations. Note that $\theta$ affects the general equilibrium equations only through its effect upon the average markup $m_{*}$.

2.9. Balanced Growth. We are especially interested in a balanced-growth equilibrium, which is a general equilibrium consistent with initial condition IC, (16)-(17), and $k_{0}=0$ and $\dot{c}_{0}=0$. In balanced growth, the Corollary to Lemma 1 shows that $Y_{t}, K_{t}$, and $C_{t}$ rise at rate $g+n$, and Lemma 1 shows that $W_{t}$ increases at rate $g$. In turn, $r_{t}=r_{*}$. A necessary condition for bounded utility with balanced growth is

$$
-\rho+\sigma n+(1-\sigma)(g+n)<0 .
$$

We assume that our model's parameters obey this. (Then, the Euler equation shows that $r_{*}>$ $n+g$.

\section{VALUE OF PATENTS}

This section characterizes the value of intangible capital-which, in our model, is the sum of the values of currently active patents. We focus on balanced-growth equilibria. 
Section 2 defined and analyzed the general equilibrium time path of the economy's inputs and outputs without specifying the division of profits between fundamental and derivative patents. That was possible because the representative household's budget constraint incorporates the full present value of all future inventions. The latter total is independent of the ownership structure. The market value of existing patents, on the other hand, will depend on the distribution of rents.

3.1. Profit Division Rules. There are many possible divisions of rent among the patents in a pool. We restrict our attention to core allocation divisions.

The presence of derivative ideas leads, for a given innovation rate $\lambda$, to larger valuations for existing intangible capital. The reason is as follows: Since a derivative invention is dependent on previous ideas, old patents can block the operation of new derivatives. This gives existing patents power over future derivatives, and the power has value. We break the total effect into two components. First, prior inventions can, in all cases, maintain their stand-alone rents until the arrival of a new fundamental idea-by threatening to not let new derivatives into the patent pool. The core allocation guarantees senior patents at least their stand-alone profit flow. In this minimal allocation, arrival of new derivative ideas merely extends the economic life of existing patents without affecting their rents. We call this the "longevity effect."

Second, blocking power potentially allows existing patents to go further and demand part, or all, of the incremental profits generated by new derivatives. We refer to this as the "blocking effect." It has been a topic of interest in the microeconomic literature. ${ }^{9}$ For example, if inventing is costly, the economy may have inefficiently low production of derivative ideas when existing patents take too large a share of new patents' rents. Conversely, production of fundamental, and early derivative, patents may be inefficiently low if they receive too small a share of complementary invention rents. Although incentives to invent are not the topic of this article, Section 5 shows how one may indirectly identify the size of the blocking effect.

We consider a family of profit-division rules parameterized by $b \in[0,1]$, with $b$ measuring our "blocking effect." Suppose that the current size of a patent pool is $h$ and the pool's market value is $v(h)$. If a new derivative idea arrives, the pool's value increases by $v(h+1)-v(h)$. Profit division rule $b$ allocates $b \cdot[v(h+1)-v(h)]$ to senior patents in the pool ${ }^{10}$ and $(1-b)$. $[v(h+1)-v(h)]$ to the new derivative. ${ }^{11}$

The rule $b=1$ represents the maximum exercise of blocking power by senior patents. All rents from derivative ideas then flow to the parent fundamental patent, and derivative patents have zero market value. The polar opposite case, $b=0$, lets a new derivative idea keep all rents that it adds to a pool. For existing patents, the "longevity effect" persists, but nothing more.

The remainder of this section derives patent pool valuations for every $b$ and $h$.

3.2. Special Case. We start with a heuristic derivation of the value intangible capital in the special case $z \geq 1 / \eta$. This case obtains when the technological step size for new inventions, $z$, is so large that the complications of limit pricing and different markups in different industries never occur. The current profit of the active patent pool equals

$$
\pi_{j t}=(1-\eta) p_{j t} x_{j t}=(1-\eta) Y_{t} \cdot\left[p_{j t}\right]^{-\frac{\eta}{1-\eta}} .
$$

When a new idea arrives in industry $j$, marginal cost falls by factor $z$. Since the markup stays constant, the price falls by factor $z$, and the pool's profit rises by factor $z^{\frac{\eta}{1-n}}$.

\footnotetext{
${ }^{9}$ See e.g., Scotchmer (1991, 1996), Chang (1995), Matutes et al. (1996), and Green and Scotchmer (1995).

10 The allocation of profit to individual senior patents can be determined recursively once $v(h)$ is known. See Section 5.4 for details.

${ }^{11} \mathrm{Chu}$ (2009) incorporates multiple profit-division rules into a model of dynamic patent pools with time-invariant markups. He assumes that each member of a pool receives a constant fraction of the current profit flow.
} 
Let $V_{j t}$ be the value of the patent pool for industry $j$. If $V_{t}$ is the aggregate value of the economy's intangible capital, then

$$
V_{t}=\int_{0}^{1} V_{j t} d j
$$

Proposition 1. Let $z>\frac{1}{\eta}$ so that $m_{j t}=\frac{1}{\eta}$ for all $j$ and $t$. Then,

$$
\dot{V}_{t}=\left(r_{t}+\gamma+\beta\right) V_{t}-\Pi_{t},
$$

where

$$
\beta=\lambda(1-\theta)-b \theta \gamma
$$

Proof. See the Appendix.

The idea is as follows: Rewrite (19) as

$$
\Pi_{t}+\dot{V}_{t}=\left[r_{t}+\lambda(1-\theta)+(1-\theta) \gamma+\theta \gamma(1-b)\right] \cdot V_{t} .
$$

The left-hand side is the economy's total income and capital gains flow from intangible capital. The right-hand side partitions the total into (i) $r_{t} V_{t}$, the private net return to beginning-of-period owners of intangible capital; (ii) $\lambda(1-\theta) V_{t}$, (compensation for) depreciation due to creative destruction; (iii) $(1-\theta) \gamma V_{t}$, returns to inventors of new fundamental ideas; and (iv) $\theta \gamma(1-$ $b$ ), gains from new derivative ideas for their inventors. To understand (iii)-(iv), note that the chance of arrival of a new fundamental idea is $(1-\theta) \lambda$. We have seen that the arrival of a new patent in industry $j$ causes $\pi_{j t}$ to jump upward by factor $z^{\frac{\eta}{1-\eta}}$. The increment to the patent pool's value is

$$
\left(z^{\frac{\eta}{1-\eta}}-1\right) V_{j t}
$$

This leads to term (iii):

$$
(1-\theta) \lambda\left(z^{\frac{\eta}{1-\eta}}-1\right) V_{j t}=(1-\theta) \gamma V_{j t}
$$

For term (iv), the chance of a new derivative invention is $\lambda \theta$, and inventors of a derivative capture only a fraction $1-b$ of the incremental value.

3.2.1. Aggregate value of intangible capital. Assume a balanced growth equilibrium with a constant markup, $m_{t}=1 / \eta$. Then, $(8)$ shows $\Pi_{t}=(1-\eta) \cdot Y_{t}$. And, $Y_{t}$ grows at rate $n+g$. Section 3.3 shows that $V_{t}$ also grows at rate $n+g$. We have noted $r_{*}>n+g$, and (20) shows $\beta$ $+\gamma \geq 0$. So, integrating (19) on $[t, \infty)$ gives

$$
V_{t}=(1-\eta) Y_{t} \cdot \int_{t}^{\infty} e^{-\left(r_{*}+\gamma+\beta\right)(s-t)} e^{(n+g)(s-t)} d s=\frac{(1-\eta) Y_{t}}{r_{*}+\beta+\gamma-(n+g)}
$$

With constant markups, $\theta$ and $b$ affect $V_{t}$ in (21) only through $\beta$. The latter parameter equals the difference between the rate of creative destruction, $\lambda(1-\theta)$, and the rate at which senior patents appropriate profits from new derivative ideas, $b \theta \gamma$-see (20). A larger $\theta$ lowers the rate 
of creative destruction, which lowers $\beta$ and raises $V_{t}$. This is our "longevity effect." Provided that $\theta>0$, a larger $b$ makes $\beta$ smaller, which again raises $V_{t}$. This is our "blocking effect."

3.2.2. Depreciation of intangible capital. The rate of depreciation for intangible capital plays an important role in our numerical calibrations below. To calculate this rate, let $V_{t, T}^{0}$ be the value at time $t+T$ of intangible capital that existed at date $t$. Then, $V_{t, 0}^{0}=V_{t}$. Using (21),

$$
\begin{aligned}
V_{t, T}^{0} & =e^{r_{*} T}(1-\eta) Y_{t} \cdot \int_{t+T}^{\infty} e^{\left(n+g-r_{*}-\gamma-\beta\right)(s-t)} d s \\
& =e^{(n+g-\gamma-\beta) T}(1-\eta) \cdot \int_{t+T}^{\infty} Y_{t} \cdot e^{\left(n+g-r_{*}-\gamma-\beta\right)(s-t-T)} d s=e^{-(\gamma+\beta-n-g) T} \cdot V_{t} .
\end{aligned}
$$

Comparing $V_{t, 0}^{0}$ with $V_{t, T}^{0}$, we can see that the value of existing intangible capital declines with age at rate $\gamma+\beta-n-g$. In other words, its "depreciation rate" (where we use this term in the same sense as the empirical literature that we rely upon for calibration in Section 5) is

$$
\Delta=\gamma+\beta-n-g=\lambda(1-\theta)-b \theta \gamma+[\gamma-n-g] .
$$

We can interpret the right-hand terms in (22) as follows: The first, $\lambda(1-\theta)$, measures depreciation due to creative destruction. The second, $-b \theta \gamma$, reflects appreciation of existing patents due to the blocking effect. To understand the third term, consider expressions (18) and (4). Population growth and inventions in other industries raise $Y_{t}$; thus, with a fixed $Z_{j t}$, industry $j$ can sell proportionately more. Accordingly, $x_{j t}$ and $\pi_{j t}$ tend to rise at the balanced-growth rate for $Y_{t}, n+g$. On the other hand, TFP growth in other industries raises the wage-at balanced-growth rate $g$. With $Z_{j t}$ staying fixed, marginal cost $c_{j t}$ then rises at rate $(1-\alpha) \cdot g$. Given a constant markup, the rising marginal cost makes $\pi_{j t}$ fall at rate $\frac{\eta}{1-\eta} \cdot(1-\alpha) \cdot g=\gamma$ (see (16)). Therefore, innovations in other sectors cause profits (and patent value) in industries with stagnating TFP to decay at rate $\gamma-n-g$. This is reminiscent of obsolescence in Solow (1960), and we call $\gamma-n-g$ our "obsolescence" term.

3.3. General Case. This section derives the law of motion for the aggregate value of patents in the general case $H \geq 1$.

Three variables characterize the state of industry $j$ at time $t \geq 0$ : its markup state $h$, the number of innovations $N$ after $t=0$, and $Z_{j 0}$. Thus, for $t>0$,

$$
\begin{aligned}
\pi_{j t} & =\pi_{t}\left(h_{j t}, N_{j t}, Z_{j 0}\right), \\
V_{j t} & =v_{t}\left(h_{j t}, N_{j t}, Z_{j 0}\right) .
\end{aligned}
$$

Assumption (IC) makes the distributions of $h_{j t}, N_{j t}$, and $Z_{j 0}$ independent of one another. The aggregative values of profits and intangible capital for patent pools with $h_{j t}=h$ and $N_{j t}=N$ are the same as the expected values with respect to the distribution of $Z_{j 0}$ :

$$
\begin{gathered}
\pi_{t}(h, N)=\mathbb{E}\left(\pi_{t}\left(h_{j t}, N_{j t}, Z_{j 0}\right) \mid h_{j t}=h, N_{j t}=N\right), \\
v_{t}(h, N)=\mathbb{E}\left(v_{t}\left(h_{j t}, N_{j t}, Z_{j 0}\right) \mid h_{j t}=h, N_{j t}=N\right) .
\end{gathered}
$$

Consider an industry in state $(h, N)$ at time $t$. The patent pool receives a profit flow until the next Poisson event, which occurs, say, at time $\tau$. At the Poisson event, with probability $1-\theta$, the patent pool depreciates completely, and with probability $\theta$, the new derivative idea appears and the pool receives fraction $b$ of its incremental value, $b\left(v_{\tau}(h \oplus 1, N+1)-v_{\tau}(h, N+1)\right)$, where $h \oplus 1=\min \{h+1, H\}$. Thus, for any $h=1, \ldots, H$, value function $v_{t}(h, N)$ obeys a 
recursion $^{12}$

(23) $v_{t}(h, N)$

$$
=\int_{t}^{\infty} \lambda e^{-\lambda(\tau-t)}\left(\int_{t}^{\tau} e^{-\bar{r}(t, s)} \pi_{s}(h, N) d s+e^{-\bar{r}(t, \tau)} \cdot \theta\left[(1-b) v_{\tau}(h, N)+b v_{\tau}(h \oplus 1, N+1)\right]\right) d \tau .
$$

The following lemma derives an expression for $\pi_{t}(h, N)$ and the law of motion for $v_{t}(h, N)$ :

Lemma 2. Assume initial condition IC. Then, average equilibrium profit for an industry in state $(h, N)$ is

$$
\pi_{t}(h, N)=\mu_{h} \cdot Y_{t} \cdot e^{-\gamma t} \cdot z^{N \frac{\eta}{1-\eta}},
$$

where

$$
\vec{\mu}=\frac{[\vec{m}]^{-\frac{\eta}{1-\eta}}-[\vec{m}]^{-\frac{1}{1-\eta}}}{\left(\vec{a}_{*} \cdot \vec{m}^{-\frac{\eta}{1-\eta}}\right)}
$$

For all $(h, N)$,

$$
v_{t}(h, N)=v_{t}(h, 0) \cdot z^{N \frac{\eta}{1-\eta}}
$$

The law of motion for $v_{t}(h, 0)$ is

$$
\begin{aligned}
\dot{v}_{t}(h, 0)= & \left(\lambda+r_{t}\right) \cdot v_{t}(h, 0)-\pi_{t}(h, 0)-\lambda \theta(1-b) \cdot v_{t}(h, 0) \\
& -\lambda \theta b z^{\frac{\eta}{1-\eta}} \cdot v_{t}(h \oplus 1,0) \text { all } h=1, \ldots, H .
\end{aligned}
$$

Proof. See the Appendix.

The aggregate value of patents is the expected value of $v_{t}(\cdot)$ with respect to the distribution of states $(h, N)$ :

$$
V_{t}=\mathbb{E}\left[v_{t}(h, N)\right]=\sum_{h=1}^{H} \sum_{N=0}^{\infty} e^{-\lambda t} \frac{(\lambda t)^{N}}{N !} a_{* h} \cdot v_{t}(h, N)=e^{\gamma t} \sum_{h=1}^{H} a_{* h} \cdot v_{t}(h, 0) .
$$

The next proposition derives the law of motion for the aggregate value of patents.

Proposition 2. Assume initial condition IC. The law of motion for the aggregate value of patents is

$$
\dot{V}_{t}=\left(r_{t}+\gamma+\beta_{t}\right) V_{t}-\Pi_{t}
$$

where

$$
\beta_{t}=\lambda(1-\theta)-b \theta \lambda G_{t}
$$

\footnotetext{
${ }^{12}$ Put in other words, the function $v_{t}\left(h, N, Z_{j 0}\right)$ obeys the recursion, but we can take expected values on both sides with respect to $Z_{j 0}$, as above.
} 
and

$$
G_{t}=z^{\frac{\eta}{1-\eta}} \frac{\sum_{h=1}^{H} a_{* h} \cdot v_{t}(h \oplus 1,0)}{\sum_{h=1}^{H} a_{* h} \cdot v_{t}(h, 0)}-1 .
$$

Proof. See the Appendix.

The law of motion for the value of patents is similar to that derived for the special case of Proposition 1: When $H=1, G_{t}=z^{\frac{\eta}{1-\eta}}-1=\gamma / \lambda$, and expression (29) collapses to $\beta$ from Proposition 1.

3.3.1. Balanced-growth path. On the balanced-growth path, output $Y_{t}$ grows at rate $g+$ $n$, and as Lemma 2 shows, average industry profits $\pi_{t}(h, 0)$ and patent values $v_{t}(h, 0)$ grow at rate $g+n-\gamma$. So, (28) shows $V_{t}$ grows at rate $n+g$. Define vectors

$$
\vec{u}(t)=\frac{1}{Y_{t} e^{-\gamma t}}\left(\begin{array}{c}
v_{t}(1,0) \\
\ldots \\
v_{t}(H-1,0) \\
v_{t}(h, 0)
\end{array}\right), \quad \vec{u}^{+}(t)=\frac{1}{Y_{t} e^{-\gamma t}}\left(\begin{array}{c}
v_{t}(2,0) \\
\ldots \\
v_{t}(h, 0) \\
v_{t}(h, 0)
\end{array}\right)
$$

that correspond to detrended patent values in each of the markup states. On the balancedgrowth path, $\vec{u}(t)$ is a vector of constants $\vec{u}_{*}$. Equation (27) determines the components of $\vec{u}_{*}$ :

$$
\left(\lambda+\gamma+r_{*}-n-g\right) \vec{u}_{*}-\lambda \theta(1-b) \vec{u}_{*}=\vec{\mu}+\theta b(\lambda+\gamma) \vec{u}_{*}^{+} .
$$

The balanced-growth ratio of intangible to GDP $V_{t} / Y_{t}$ can be expressed through $\vec{u}_{*}$ as

$$
\frac{V_{t}}{Y_{t}}=\vec{a}_{*} \cdot \vec{u}_{*}=\frac{\vec{a}_{*} \cdot \vec{\mu}}{r_{*}+\Delta_{*}}
$$

where

$$
\Delta_{*}=\lambda(1-\theta)-b \theta \lambda G_{*}+\gamma-n-g
$$

is the steady-state depreciation rate on intangible capital. Expression (32) is analogous to (21), except its numerator, $\vec{a}_{*} \cdot \vec{\mu}$, takes into account multiple markup states. Expression (33) is analogous to (22), except $G_{*}$ measures the average profit gain from a new derivative idea across multiple markup states. ${ }^{13}$

To quantitatively assess the implications of our model for the aggregate value of intangible capital, we next calibrate the model's parameters.

\section{MEASUREMENT}

This section proposes a method for using microdata on U.S. patents to calibrate key parameters $\lambda$ and $\theta$, which describe the rate of innovation and the fraction of derivative ideas.

\footnotetext{
13 As in Section 3.2, we need $r_{*}+\Delta_{*}>0$. This is not a problem for the analysis, since Section 5 calibrates $b$ so that $\Delta_{*}$ matches a positive number-see below.
} 
Our procedure is as follows: We want to think of the pooled time series of cross sections of data on individual patents as composed of distinct sequences of related patents-with the latter corresponding to Figure 1 in Section 1. In a sequence, a fundamental patent makes no citations, but derivative patents cite their parent fundamental patent and the intervening derivatives. In this framework, the minimum citation lag from the data provides information about $\lambda$, shorter minimum citation lags being associated with a higher $\lambda$ (i.e., more frequent inventions). And the maximum lag provides information about $\theta$, longer gaps between fundamental ideas being associated with higher values of $\theta$ (i.e., more derivative patents). (The Appendix explains why we choose to work with citation lags instead of counts of patents or citations.)

4.1. Description of the Data. Our data come from the NBER U.S. Patent Citations Data File (Hall et al., 2001), which has a complete record of all citations made by patents granted in 1975-1999, and detailed information on all U.S. patents granted in 1963-1999. We restrict our sample to patents either assigned to (i.e., owned by) domestic companies or individuals or granted to U.S. inventors. The restricted sample includes 1,222,202 patents and 7,056,477 citations.

4.2. Parameter Measurements. We estimate $\lambda$ and $\theta$ as follows: Looking at the list of citations made (in the same industry) by each new patent, we record the shortest and longest citation lags. (The citation lag is defined as the age of the cited patent at the time the citation is made.) In the model, a patent that makes at least one citation should necessarily cite the preceding idea, whether the latter is fundamental or derivative. Therefore, the minimum citation lag should have mean $1 / \lambda$. On the other hand, the oldest cited patent should be the parent fundamental idea, which implies that the maximum citation lag has mean $\frac{1}{\lambda(1-\theta)}$. Observations on mean minimum and maximum citation lags can thus pin down $\lambda>0$ and $\theta<1$.

Figure 2 presents minimum and maximum citation lags, restricting citations to patents in the same two- or three-digit industry-or making no restriction at all. The maximal span of citation lags in the sample for patent grants in 1975 is 12 years; therefore, to avoid truncation bias in visual comparisons, Figure 2 includes only citations less than 13 years old. We focus on the three-digit industry case, which seems the closest in spirit to our model. ${ }^{14}$

Our data analysis proceeds as follows: We utilize backward citation lags (that is to say, lags for citations made instead of citations received) in windows of up to 18 years. For patent grants in 1975, we can observe lags up to 13 years. For grants in 1976, we observe lags of up to 14 years, and so on. For 1980 and beyond, we allow lags of 18 years or less, covering all citations to unexpired patents. ${ }^{15}$ We derive the stationary-state relationship between citation lags and $\lambda$ and $\theta$ and use the method of moments to estimate parameter values.

Let $T$ be the longest patent citation lag processed for citations made in year $t$. Let $S_{j t}$ denote a random variable equal to the maximum citation lag among citations made by the most recent patent in industry $j$, and let $s_{j t}$ denote the minimum citation lag for the same patent. If our Poisson arrival process and fundamental/derivative division dictated by $\theta$ have generated stationary distributions of fundamental and derivative patents in our data, then

Proposition 3. For any $\lambda, T>0$ and any $\theta \in(0,1)$

$$
\mathbb{E}\left(s_{j t} \mid D_{j t}>0, s_{j t} \leq T\right)=\bar{s}(\lambda, T)=\frac{1}{\lambda}\left(1-\frac{\lambda T}{e^{\lambda T}-1}\right)
$$

\footnotetext{
14 Thompson and Fox-Kean (2005) note that definitions of USPTO patent classes do not correspond exactly to U.S. industry classifications.

${ }^{15}$ For a patent granted $1 / 1 / 75$, our data cover cited patents originating as early as $1 / 1 / 63$ - a lag of 12 years. For a patent granted 12/31/75, the earliest usable citation remains $1 / 1 / 63$ - a lag of 13 years. Hence, lag calculations below set a citation window for patents granted $t=1975$ of $[t-T, t), T=12.5$, etc. For patent grants $t \geq 1980$, we set $T=17.5$.
} 


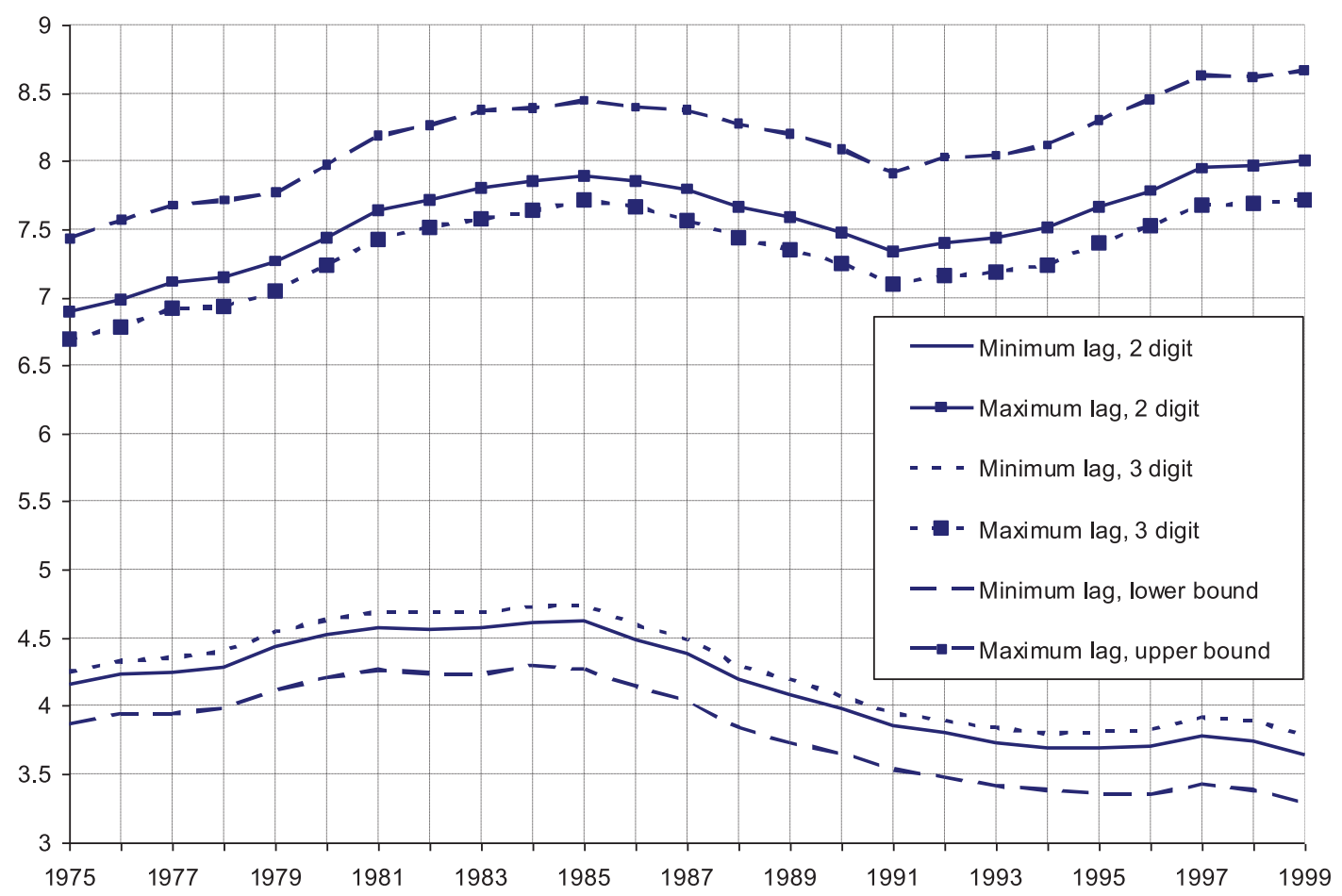

FIGURE 2

MINIMUM AND MAXIMUM BACKWARD CITATION LAGS, MEAN ACROSS PATENTS BY YEAR, CONDITIONAL ON LAG SHORTER THAN 13 YEARS

$$
\mathbb{E}\left(S_{j t} \mid D_{j t}>0, S_{j t} \leq T\right)=\bar{S}(\lambda, \theta, T)=\frac{1}{\lambda(1-\theta)}\left(1-\frac{\lambda T}{e^{\lambda T}-1}-\frac{e^{\lambda T \theta}-1-\lambda T \theta}{\theta\left(e^{\lambda T}-1\right)}\right)
$$

Proof. See the Appendix.

Table 1 presents two sets of parameter estimates. The first set determines $\lambda$ and $\theta$ from two moment conditions that match the minimum and maximum citation lags in (34)-(35) with their sample means. To provide a consistency check, the second set of estimates uses (34)-(35) together with a third, overidentifying moment condition that matches the fraction of patents making at least one citation in the window $[t-T, t)$,

$$
\theta \cdot\left(1-e^{-\lambda T}\right)
$$

with its counterpart in the data. The point estimates between the two sets are very close. In all cases, the point estimates of $\theta$ are significantly different from 0 and 1 , supporting the specification with two types of ideas.

In sum, Table 1 gives reasonably constant estimates of $\lambda$ and $\theta$, consistent with our stationarity assumptions. A more detailed look at Table 1 shows that $\theta$ seems to rise modestly in 1975-85, and $\lambda$ somewhat more steeply in 1990-99. Though the length of our series is too short to judge whether these changes represent trends or random fluctuations, Section 5.3 investigates the potential sensitivity of macroeconomic variables of interest to the range of values for both parameters evident in Table 1.

4.2.1. Discussion. As stated above, our estimation procedure only uses "qualified" citations, i.e., citations made to unexpired patents within own industry. This is consistent with the logic of our model, where within-industry citations, or lack thereof, determine the limit price 
TABLE 1

ESTIMATES OF $\lambda$ AND $\theta$ (STANDARD ERRORS IN PARENTHESES)

\begin{tabular}{|c|c|c|c|c|c|c|c|}
\hline \multirow[b]{2}{*}{ Year } & \multirow[b]{2}{*}{$T$} & \multicolumn{3}{|c|}{ Two Moments: (34)-(35) } & \multicolumn{3}{|c|}{ Three Moments: (34)-(36) } \\
\hline & & $\lambda$ & $\theta$ & Nobs & $\lambda$ & $\theta$ & Nobs \\
\hline 1975 & 12.5 & $\begin{array}{c}0.1642 \\
(0.0015)\end{array}$ & $\begin{array}{c}0.7205 \\
(0.0038)\end{array}$ & 30625 & $\begin{array}{c}0.1642 \\
(0.0013)\end{array}$ & $\begin{array}{c}0.7400 \\
(0.0025)\end{array}$ & 46740 \\
\hline 1976 & 13.5 & $\begin{array}{c}0.1612 \\
(0.0015)\end{array}$ & $\begin{array}{c}0.7078 \\
(0.0036)\end{array}$ & 30057 & $\begin{array}{c}0.1612 \\
(0.0012)\end{array}$ & $\begin{array}{c}0.7412 \\
(0.0024)\end{array}$ & 44487 \\
\hline 1977 & 14.5 & $\begin{array}{c}0.1642 \\
(0.0014)\end{array}$ & $\begin{array}{c}0.6989 \\
(0.0034)\end{array}$ & 28721 & $\begin{array}{c}0.1644 \\
(0.0012)\end{array}$ & $\begin{array}{c}0.7336 \\
(0.0019)\end{array}$ & 41773 \\
\hline 1978 & 15.5 & $\begin{array}{c}0.1584 \\
(0.0014)\end{array}$ & $\begin{array}{c}0.6956 \\
(0.0033)\end{array}$ & 28899 & $\begin{array}{c}0.1587 \\
(0.0011)\end{array}$ & $\begin{array}{c}0.7313 \\
(0.0017)\end{array}$ & 41773 \\
\hline 1979 & 16.5 & $\begin{array}{c}0.1484 \\
(0.0015)\end{array}$ & $\begin{array}{c}0.7132 \\
(0.0038)\end{array}$ & 21475 & $\begin{array}{c}0.1484 \\
(0.0012)\end{array}$ & $\begin{array}{c}0.7497 \\
(0.0024)\end{array}$ & 30309 \\
\hline 1980 & 17.5 & $\begin{array}{c}0.1445 \\
(0.0012)\end{array}$ & $\begin{array}{c}0.7377 \\
(0.0032)\end{array}$ & 27425 & $\begin{array}{c}0.1445 \\
(0.0010)\end{array}$ & $\begin{array}{c}0.7692 \\
(0.0021)\end{array}$ & 37595 \\
\hline 1981 & 17.5 & $\begin{array}{c}0.1397 \\
(0.0012)\end{array}$ & $\begin{array}{c}0.7693 \\
(0.0032)\end{array}$ & 28983 & $\begin{array}{c}0.1396 \\
(0.0010)\end{array}$ & $\begin{array}{c}0.7867 \\
(0.0021)\end{array}$ & 39697 \\
\hline 1982 & 17.5 & $\begin{array}{c}0.1388 \\
(0.0013)\end{array}$ & $\begin{array}{c}0.7877 \\
(0.0035)\end{array}$ & 25395 & $\begin{array}{c}0.1387 \\
(0.0011)\end{array}$ & $\begin{array}{c}0.8013 \\
(0.0022)\end{array}$ & 34336 \\
\hline 1983 & 17.5 & $\begin{array}{c}0.1392 \\
(0.0013)\end{array}$ & $\begin{array}{c}0.7938 \\
(0.0036)\end{array}$ & 24387 & $\begin{array}{c}0.1391 \\
(0.0011)\end{array}$ & $\begin{array}{c}0.7996 \\
(0.0024)\end{array}$ & 33251 \\
\hline 1984 & 17.5 & $\begin{array}{c}0.1355 \\
(0.0012)\end{array}$ & $\begin{array}{c}0.8119 \\
(0.0034)\end{array}$ & 28621 & $\begin{array}{c}0.1355 \\
(0.0010)\end{array}$ & $\begin{array}{c}0.8116 \\
(0.0023)\end{array}$ & 38910 \\
\hline 1985 & 17.5 & $\begin{array}{c}0.1323 \\
(0.0012)\end{array}$ & $\begin{array}{c}0.8310 \\
(0.0035)\end{array}$ & 29440 & $\begin{array}{c}0.1324 \\
(0.0010)\end{array}$ & $\begin{array}{c}0.8171 \\
(0.0027)\end{array}$ & 40446 \\
\hline 1986 & 17.5 & $\begin{array}{c}0.1375 \\
(0.0013)\end{array}$ & $\begin{array}{c}0.8377 \\
(0.0035)\end{array}$ & 28285 & $\begin{array}{c}0.1376 \\
(0.0011)\end{array}$ & $\begin{array}{c}0.8145 \\
(0.0026)\end{array}$ & 38967 \\
\hline 1987 & 17.5 & $\begin{array}{c}0.1441 \\
(0.0012)\end{array}$ & $\begin{array}{c}0.8343 \\
(0.0031)\end{array}$ & 32733 & $\begin{array}{c}0.1442 \\
(0.0010)\end{array}$ & $\begin{array}{c}0.8133 \\
(0.0022)\end{array}$ & 44613 \\
\hline 1988 & 17.5 & $\begin{array}{c}0.1523 \\
(0.0013)\end{array}$ & $\begin{array}{c}0.8311 \\
(0.0030)\end{array}$ & 30616 & $\begin{array}{c}0.1523 \\
(0.0011)\end{array}$ & $\begin{array}{c}0.8088 \\
(0.0020)\end{array}$ & 41559 \\
\hline 1989 & 17.5 & $\begin{array}{c}0.1611 \\
(0.0012)\end{array}$ & $\begin{array}{c}0.8174 \\
(0.0025)\end{array}$ & 38263 & $\begin{array}{c}0.1609 \\
(0.0010)\end{array}$ & $\begin{array}{c}0.8008 \\
(0.0017)\end{array}$ & 51692 \\
\hline 1990 & 17.5 & $\begin{array}{c}0.1690 \\
(0.0012)\end{array}$ & $\begin{array}{c}0.8124 \\
(0.0025)\end{array}$ & 35961 & $\begin{array}{c}0.1686 \\
(0.0011)\end{array}$ & $\begin{array}{c}0.7949 \\
(0.0017)\end{array}$ & 48635 \\
\hline 1991 & 17.5 & $\begin{array}{c}0.1805 \\
(0.0012)\end{array}$ & $\begin{array}{c}0.7964 \\
(0.0022)\end{array}$ & 38883 & $\begin{array}{c}0.1801 \\
(0.0010)\end{array}$ & $\begin{array}{c}0.7856 \\
(0.0018)\end{array}$ & 52340 \\
\hline 1992 & 17.5 & $\begin{array}{c}0.1885 \\
(0.0012)\end{array}$ & $\begin{array}{c}0.7857 \\
(0.0021)\end{array}$ & 39581 & $\begin{array}{c}0.1883 \\
(0.0011)\end{array}$ & $\begin{array}{c}0.7800 \\
(0.0017)\end{array}$ & 53059 \\
\hline 1993 & 17.5 & $\begin{array}{c}0.1984 \\
(0.0012)\end{array}$ & $\begin{array}{c}0.7772 \\
(0.0020)\end{array}$ & 40668 & $\begin{array}{c}0.1983 \\
(0.0010)\end{array}$ & $\begin{array}{c}0.7765 \\
(0.0014)\end{array}$ & 54106 \\
\hline 1994 & 17.5 & $\begin{array}{c}0.2054 \\
(0.0011)\end{array}$ & $\begin{array}{c}0.7784 \\
(0.0018)\end{array}$ & 43708 & $\begin{array}{c}0.2058 \\
(0.0010)\end{array}$ & $\begin{array}{c}0.7842 \\
(0.0008)\end{array}$ & 56841 \\
\hline 1995 & 17.5 & $\begin{array}{c}0.2079 \\
(0.0011)\end{array}$ & $\begin{array}{c}0.7823 \\
(0.0017)\end{array}$ & 44049 & $\begin{array}{c}0.2084 \\
(0.0010)\end{array}$ & $\begin{array}{c}0.7880 \\
(0.0008)\end{array}$ & 56920 \\
\hline 1996 & 17.5 & $\begin{array}{c}0.2114 \\
(0.0011)\end{array}$ & $\begin{array}{c}0.7755 \\
(0.0016)\end{array}$ & 48508 & $\begin{array}{c}0.2123 \\
(0.0009)\end{array}$ & $\begin{array}{c}0.7848 \\
(0.0005)\end{array}$ & 62470 \\
\hline 1997 & 17.5 & $\begin{array}{c}0.2069 \\
(0.0010)\end{array}$ & $\begin{array}{c}0.7892 \\
(0.0016)\end{array}$ & 48978 & $\begin{array}{c}0.2072 \\
(0.0009)\end{array}$ & $\begin{array}{c}0.7928 \\
(0.0009)\end{array}$ & 63134 \\
\hline 1998 & 17.5 & $\begin{array}{c}0.2105 \\
(0.0009)\end{array}$ & $\begin{array}{c}0.7823 \\
(0.0014)\end{array}$ & 64321 & $\begin{array}{c}0.2112 \\
(0.0008)\end{array}$ & $\begin{array}{c}0.7903 \\
(0.0006)\end{array}$ & 82460 \\
\hline 1999 & 17.5 & $\begin{array}{c}0.2174 \\
(0.0009)\end{array}$ & $\begin{array}{c}0.7847 \\
(0.0013)\end{array}$ & 67258 & $\begin{array}{c}0.2180 \\
(0.0008)\end{array}$ & $\begin{array}{c}0.7910 \\
(0.0005)\end{array}$ & 86089 \\
\hline & & & Colu & rages & & & \\
\hline 1980-99 & & 0.1710 & 0.7958 & & 0.1711 & 0.7946 & \\
\hline 1975-79 & & 0.1593 & 0.7072 & & 0.1594 & 0.7392 & \\
\hline 1980-89 & & 0.1425 & 0.8052 & & 0.1425 & 0.8023 & \\
\hline 1990-99 & & 0.1996 & 0.7864 & & 0.1998 & 0.7868 & \\
\hline
\end{tabular}


and creative destruction. In the data, we can define derivative ideas as patents that make at least one qualified citation, and fundamental ideas as those citing either outside of their industry or not at all. ${ }^{16}$ Condition (36) provides a consistency check. For instance, we can take the estimates of $\lambda$ and $\theta$ based on (34)-(35) and predict the fraction of patents making at least one qualified citation from (36). For the time intervals 1975-79, 1980-89, and 1990-99, the agreement seems very good: predictions from (36) are $0.64,0.74$, and 0.76 , respectively, whereas the corresponding fractions in the data are $0.68,0.73$, and 0.76 . Because the estimates from citation lags (34)-(35) are in agreement with (36), adding the third moment condition has little effect on the estimates of $\lambda$ and $\theta$ in Table 1.

Following much of the literature, our model associates patent citations with the division of property rights between complementary patents. In reality, some patents may cite substitutes whose value they destroy. They might do so, for example, to establish their own novelty. Fundamental patents would presumably be the ones having the most reason to cite substitutes. Our estimation procedure remains robust to this variation in assumptions about citation activity. Assume, in particular, a new citation rule where derivative ideas cite their complements from the current patent pool (exactly as before) and fundamental ideas cite their substitutes, i.e., all of the patents from the pool they destroy. Under the new citation rule, the distributions of backward citation lags for fundamental and derivative patents are identical. This is because fundamental and derivative ideas are assumed to cite all patents in their industry's pool (either previous or current), and the cross-sectional composition of patent pools is independent of whether the most recent innovation is fundamental or derivative. Consequently, expressions (34)-(35) (derived under the assumption that only derivative ideas make citations) remain valid, and the corresponding parameter estimates are unaffected. On the other hand, if citation of substitutes were prevalent, the fraction of patents making at least one qualified citation would have to equal $1-e^{-\lambda T}$, which exceeds (36). Since our analysis finds consistency between (34)(35) and (36), we conclude that citation of substitutes within own industry must be rare in practice.

Our estimation procedure may remain applicable for more complex citation networks than those that we assume (see Belenzon, 2006). For example, if one fundamental idea gives rise to multiple streams of derivatives, minimum and maximum citation lags will correctly identify the previous derivative in a thread and the parent fundamental idea. If, on the other hand, a derivative idea originates from multiple fundamental ideas and all of them are cited, the maximum citation lag will pick up the oldest "parent" fundamental idea. Similarly, if a derivative idea is based on multiple "converging" streams, our procedure will identify its most recent predecessor across all such streams. Our procedure is also robust if a derivative idea cites its fundamental "parent" and its most recent predecessor, but perhaps neglects to cite some earlier derivatives.

\section{NUMERICAL RESULTS}

This section calibrates remaining parameters of our model and derives quantitative results. Section 4's estimates of $\lambda$ and $\theta$ make the analysis possible.

5.1. Calibrating the General Equilibrium Model. Our general equilibrium model depends upon $(\delta, n, \rho, \eta, z, \alpha, \sigma, \lambda, \theta)$. We employ both micro- and macrodata to complete the calibration.

First, we set conventional values $n=0.01, \rho=0.02$, and $g=0.02$. Second, from NIPA data, we set the (1952-2000) average ratio of nonresidential investment to nonhousing GDP, $i=0.136$, and labor's share, $\zeta=0.688$. Following Laitner and Stolyarov (2003), we set

\footnotetext{
${ }^{16}$ Citations to complements in other industries could lead to rent transfers across industries, although we show in Section 5 that the associated payments arising from blocking effect are small. Alternatively, connections across industries can point to important externalities (e.g., Caballero and Jaffe, 2002), and they remain an interesting topic for future research.
} 
$\delta=0.0752 .{ }^{17}$ Similarly, using aggregate financial portfolio rates of return (Laitner and Stolyarov, 2003, Appendix C), we set $r=0.1035 .{ }^{18}$ Then, we determine $\left(\alpha, \sigma, k_{*}, m_{*}\right)$ using

$$
\zeta=\frac{1-\alpha}{m_{*}}
$$

$$
\begin{gathered}
k_{*}=\left(\frac{i}{\delta+n+g}\right)^{\frac{1}{1-\alpha}}, \\
r=\frac{\alpha}{m_{*}} k_{*}^{\alpha-1}-\delta \\
\sigma=\frac{r-\rho}{g} .
\end{gathered}
$$

Expression (37) comes from Lemma 1 and labor-share data; (38) from $y_{*}-c_{*}=i \cdot k_{*}^{\alpha}$ and (17), with $\dot{k}_{t}=0$, and data on $i, g$, and $n$; (39) from (10) and data on $r$ and $\delta$; and (40) from the Euler equation, with balanced-growth outcome $\dot{C}_{t} / C_{t}=n+g$, and data on $\rho$ and $g$. Solution of (37)-(40) yields $\alpha=0.251, \sigma=4.175, m_{*}=1.088$, and $k_{*}=1.409$.

Third, we fix $\lambda$ and $\theta$ from Table 1 , take the values of $m_{*}$ and $\alpha$ from the previous step, and calibrate the remaining parameters $\eta$ and $z$ from the model's equations for the aggregate markup and productivity growth rate:

$$
\begin{gathered}
m_{*}=\frac{\vec{a}_{*} \cdot \vec{m}^{-\frac{\eta}{1-\eta}}}{\vec{a}_{*} \cdot \vec{m}^{-\frac{1}{1-\eta}}}, \\
\lambda\left(z^{\frac{\eta}{1-\eta}}-1\right) \frac{1-\eta}{\eta} \frac{1}{1-\alpha}=g .
\end{gathered}
$$

Equation (41) is the aggregate markup from Corollary to Lemma 1; Equation (42) uses (16) and (13).

5.1.1. General equilibrium results. In a standard quality ladder model, the overall rate of technological progress depends upon the product of $\lambda$ and $z$, and upon the substitution parameter $\eta$-see (42). Our approach makes component-by-component calibrations possible. Table 2 presents results.

Equations (37)-(40) yield a modest price-over-marginal cost markup factor: $m_{*}=1.088$. Several recent papers have similar estimates. Table 3 in Norrbin (1993), for example, presents weighted-average markup factors ranging from 1.04 to 1.15 . Using a dynamic model, Laitner and Stolyarov (2004) estimate factors of 1.09-1.11. ${ }^{19}$

Although our model allows markups to rise with the number of derivative inventions in an industry, each row of Table 2 has only two markup states. The markups tend to be relatively

\footnotetext{
${ }^{17}$ See Laitner and Stolyarov's (2003, Table 1) estimate of $\bar{\delta}$. For comparison, Cooley and Prescott (1995) use $\delta=$ 0.048 , McGrattan and Prescott (2000) use $\delta=0.066$ for corporate capital and 0.055 for noncorporate, and Hall et al. (2001) use $\delta=0.10$.

${ }^{18}$ Laitner and Stolyarov (2003) avoid asset and return figures beyond 1995. The stock and bond rates of return in their index come from Robert Shiller's web site. Cooley and Prescott (1995), for example, use $r=0.069$; Pakes (1986), $r=0.10$; and Hall et al. (2001, p. 1186), $r=0.077$.

${ }^{19}$ See also Rotemberg and Woodford (1995), Jones and Williams (2000), Basu and Fernald (1997), and Atkeson and Kehoe (2005).
} 
TABLE 2

GENERAL EQUILIBRIUM CALIBRATION WITH $\alpha=0.251, \sigma=4.175, m_{*}=1.088$, AND $k_{*}=1.409$

\begin{tabular}{|c|c|c|c|c|c|c|c|c|}
\hline \multicolumn{2}{|c|}{ Table 1 Data } & \multicolumn{7}{|c|}{ Outcomes } \\
\hline$\lambda$ & $\theta$ & $\eta$ & $z$ & $H$ & $\vec{m}_{*}$ & $\bar{m}$ & $\lambda(1-z)$ & $g_{z}$ \\
\hline 0.1710 & 0.7958 & 0.9118 & 1.0643 & 2 & $(1.0643,1.0967)$ & 0.9991 & 0.0110 & 0.015 \\
\hline 0.1593 & 0.7072 & 0.9096 & 1.0684 & 2 & $(1.0684,1.0993)$ & 0.9990 & 0.0109 & 0.015 \\
\hline 0.1425 & 0.8052 & 0.9151 & 1.0728 & 2 & $(1.0728,1.0927)$ & 0.9997 & 0.0104 & 0.015 \\
\hline 0.1996 & 0.7864 & 0.9083 & 1.0577 & 2 & $(1.0577,1.1009)$ & 0.9983 & 0.0115 & 0.015 \\
\hline
\end{tabular}

similar across states. Furthermore, the calibrations of $\vec{a}_{*}=(1-\theta, \theta)$ assign about $80 \%$ of industries to the second state at any given time. In the end, Table 2 predicts roughly constant markups throughout the economy.

The distribution of markups across industries impacts resource allocation efficiency. The Corollary to Lemma 1 shows that the economy's aggregate TFP level has a static efficiency term, $\bar{m}$, that enters multiplicatively. If different intermediate-good industries have different markups, resulting factor allocation distortions cause $\bar{m}<1$. On the other hand, if all markups are the same, distortionary effects exactly cancel, leaving $\bar{m}=1$. Table 2 , column 7 , shows that the similarity of markups, and their distribution, leads to values of $\bar{m}$ very close to 1 - the static factor allocation distortion is not quantitatively significant.

The model's multiple sectors give rise to a dynamic effect in the aggregate production function as well, manifested in the growth rate of $Z_{t}$. The intuitive idea is as follows: With independent Poisson processes, intersectoral TFP differences emerge and expand over time. Intermediategood output imbalances tend to reduce GDP (via Jensen's inequality) in (1). On the other hand, the economy gains from the opportunity to allocate more inputs to the highest TFP industries. The better the substitution possibilities among intermediate goods, the more the input allocation effect will tend to outweigh the imbalance effect.

Specifically, the industry long-run average rate of TFP growth is

$$
g_{Z_{j}}=\lambda \cdot(z-1) \text {. }
$$

On the other hand, (12)-(13) show that the aggregate rate of TFP growth is ${ }^{20}$

$$
g_{Z}=\lambda\left(z^{\frac{\eta}{1-\eta}}-1\right) \frac{1-\eta}{\eta}
$$

In the above expression, $g_{Z}$ positively depends on $\eta$, and $g_{Z}$ exceeds $\lambda \cdot(z-1)$ when $\eta$ exceeds $1 / 2$. This is to say that for $\eta>1 / 2$, the input allocation effect dominates the TFP imbalance effect, and aggregate TFP growth exceeds industry average TFP growth.

If the equilibrium markup is modest, one should expect that outputs of different sectors are good substitutes. This is what we find in Table 2. The value of $\eta$ in column 3 is around 0.9 , leading to a large elasticity of substitution across industries and a big effect of leading sectors on aggregate TFP growth. The last two columns of Table 2 show the quantitative impact. Although a single industry has average TFP growth of $1.0-1.15 \%$ per year, the substitution of inputs toward leading industries raises the aggregate TFP growth to $1.5 \%$ per year for the same $\lambda$ and $z$.

5.2. Intangible Capital. Our model's intangible capital stock, $V_{t}$, is the sum of the market values of existing, active patents. Section 3 shows that to determine $V_{t}$, we need to calibrate one additional parameter $b$.

${ }^{20}$ Note that $(6)$ implies $g=g_{Z} /(1-\alpha)$. 
TABLE 3

VALUATION CALIBRATION WITH $\alpha=0.251, \sigma=4.175, m_{*}=1.088$, AND $k_{*}=1.409$

\begin{tabular}{|c|c|c|c|c|c|c|c|}
\hline \multicolumn{2}{|c|}{ Table 1 Data } & \multirow[b]{2}{*}{$\Delta_{*}$} & \multirow[b]{2}{*}{$b$} & \multicolumn{4}{|c|}{ Outcomes } \\
\hline$\lambda$ & $\theta$ & & & $V_{t} / Y_{t}$ & $K_{t} / Y_{t}$ & $Q_{t}$ & $\omega_{t}$ \\
\hline \multicolumn{8}{|c|}{ Panel 1: Results given $\Delta_{*}=0.15$ with $b$ determined from (43) } \\
\hline 0.1710 & 0.7958 & 0.15 & 0.0772 & 0.3195 & 1.2928 & 1.2471 & 1.6122 \\
\hline 0.1593 & 0.7072 & 0.15 & 0.1583 & 0.3194 & 1.2928 & 1.2471 & 1.6122 \\
\hline 0.1425 & 0.8052 & 0.15 & 0.0703 & 0.3195 & 1.2928 & 1.2471 & 1.6122 \\
\hline 0.1996 & 0.7864 & 0.15 & 0.0895 & 0.3195 & 1.2928 & 1.2471 & 1.6122 \\
\hline \multicolumn{8}{|c|}{ Panel 2: Results for selected $b$ with $\Delta_{*}$ determined from (43) } \\
\hline 0.1710 & 0.7958 & 0.1598 & 0 & 0.3076 & 1.2928 & 1.2379 & 1.6004 \\
\hline 0.1710 & 0.7958 & 0.0971 & 0.5 & 0.4037 & 1.2928 & 1.3123 & 1.6965 \\
\hline 0.1710 & 0.7958 & 0.0353 & 1 & 0.5834 & 1.2928 & 1.4513 & 1.8761 \\
\hline
\end{tabular}

5.2.1. The blocking effect. To set $b$, we match our model's depreciation rate for intangible capital to a measure from the literature. Section 3.2 shows that the model's depreciation rate for $V_{t}$ is $\Delta$. In the generalized formulation of Section 3.3, the deprecation rate varies with time through $G_{t}$. However, in balanced growth, even the generalized rate is constant-see $\Delta_{*}$ in (33).

Using European data on patent renewal rates, Pakes and Schankerman (1984) estimate a depreciation rate of 0.25 ; from similar data but a somewhat more sophisticated formulation, Schankerman and Pakes (1986) estimate 0.10-0.18; and Pakes (1986) estimates 0.11-0.19. Using a different methodology based on factor demands, Nadiri and Prucha (1996, Table 1) estimate a depreciation rate on $R \& D$ capital of 0.12 .

Hall et al. (2005) provide independent evidence. Assuming a depreciation rate of $15 \%$ per year, they compute the net values of patents held by Compustat manufacturing corporations. Regressing the net values on past and future citations (measured ex post), they find a very small coefficient on past citations. Our analysis suggests that past citations are a proxy for patent age. If the $15 \%$ depreciation rate for intangible capital were too low (high), age would have a negative (positive) regression coefficient. Hence, the $15 \%$ estimate seems reinforced. ${ }^{21}$

Using a depreciation rate of $0.15,(33)$ yields

$$
\Delta_{*}=\lambda(1-\theta)-b \theta \lambda G_{*}+\gamma-n-g=0.15 \text {. }
$$

Setting other parameters as in Table 2, we calibrate $b$ from this expression. The top panel of Table 3 presents outcomes. They are consistent with the constraint $b \in[0,1]$.

The calibrated values of $b$ in Panel 1 lie at the lower end of the domain [0,1]. We require that blocking power guarantees senior patents at least their stand-alone value. If senior patents exercise their power more fully, $b>0$ should give rise to our blocking effect. Panel 1 shows this to be small in all cases.

The magnitude of $b$ has microeconomic implications. If $b$ is larger, the value of existing patents will tend to be greater because their owners anticipate capturing the rents from future derivative inventions. In a framework with $\mathrm{R} \& \mathrm{D}$, a large $b$ creates especially strong incentives for developing fundamental inventions. Derivative inventions then either must have low development costs or funding from the owners of fundamental patents. When $b$ is low, incentives to develop derivative inventions are better-but worse for fundamental inventions.

\footnotetext{
${ }^{21}$ Hall et al. (2005, Table 3) show a large, positive coefficient on the future citations regressor. In our model, creative destruction is one reason why future citations may correlate with high market value of a patent. Agents within the economy presumably observe the arrival of a new fundamental invention; thus, creative destruction should immediately reduce the value of replaced patents. These same patents are the ones that will have no future citations. An econometrician, by contrast, may only learn of destruction gradually, through the absence of continuing citation activity for particular older patents.
} 
In this light, Hall et al. (2005, Table 1) provide indirect evidence supporting a low $b$. If $b \approx$ 1 , we might expect the owners of fundamental inventions to hold most derivative patents, since other agents would value them less. Yet, the sample in Hall et al. (2005) shows the reverse. Their corporations tend to be large, holding an average of about 200 patents. In terms of citations received, however, their Table 1 shows that only about $9 \%$ are "self-citations"-i.e., citations from a firm's own patents. If firms tend to hold entire patent pools, self-citations could approach $100 \%$. Evidently, corporations' holdings are diverse in practice instead of concentrated.

Panel 2 of Table 3 imposes various values of $b \in[0,1]$ and calculates $\Delta_{*}$ from the left-hand side of (33). Setting $b=0.0$ yields a $\Delta_{*}$ squarely in the range of the Pakes-Schankerman estimates, $b=0.5$ yields $\Delta_{*}$ marginally beneath the range, and $b=1.0$ gives a $\Delta_{*}$ far below. Results-not shown-for other $(\lambda, \theta)$ pairs from Table 1 are very similar. In the end, there seems to be little support for a large $b .^{22}$

5.2.2. Value of intangible capital. The right-hand columns of Table 3 provide the model's ratios of intangible and tangible capital to output, $V_{t} / Y_{t}$ and $V_{t} / K_{t}$, as well as Tobin's average Q,

$$
Q_{t}=1+\frac{V_{t}}{K_{t}}
$$

and the ratio of the market value of businesses to GDP,

$$
\omega_{t}=\frac{V_{t}+K_{t}}{Y_{t}}
$$

In all cases, we focus on balanced-growth equilibria, for which the ratios are constant.

In the first row of Table 3, which utilizes our longest sample from the patent data, $V_{t} / Y_{t}$ is about 0.32 and $Q_{*}$ is 1.25 . Valuations in the remaining rows of Panel 1 are almost the same, because the calibrations of $\eta, \vec{a}_{*}$, and $\vec{m}_{*}$ are very similar across the rows of Table 2 .

For comparison, Laitner and Stolyarov (2003, p. 1258) estimate $Q_{*}=1.48$. In other words, they find a ratio of intangible to tangible capital that is virtually twice as high as our benchmark case. Hall et al. (2001, Figure 13) reports similar numbers for U.S. nonfinancial corporations. Hall's graph of $Q$ shows a peak around 1970 of $1.5-1.7$, and similarly for $1995 .{ }^{23}$ McGrattan and Prescott (2000, Table 1) indirectly estimate the stock of intangible capital from the residual between corporate profits and the return on tangible assets. Their ratio of corporate intangibleto-tangible capital of 0.62 compares with our $Q_{*}-1=(V / K)_{*}=0.25$.

Laitner and Stolyarov (2003) calculate an average (1952-95) $\omega_{t}=1.78$. The corresponding figure from Table 3 is 1.61. To make up the difference with intangible capital, we would need to raise our $V / Y$ from 0.32 to 0.49 , an increase of more than $50 \%$.

In sum, our model seems to explain one-third to two-thirds of U.S. intangible capital. The fact that this is far less than $100 \%$ is consistent with the fact that there are components of intangible capital other than privately owned knowledge, but not included in our analysis (e.g., Corrado et al., 2006). For example, adjustment costs for investment can raise the market value of businesses above the reproduction cost of their physical capital stock (e.g., Hall et al., 2001). Unmeasured investment expenditures in the form of deferred compensation for proprietors' labor (so-called "sweat equity") or advertising presumably augment intangible capital in practice (e.g., McGrattan and Prescott, 2005) as well.

\footnotetext{
${ }^{22}$ Using $\Delta_{*}=0.12$ as in Nadiri and Prucha (1996) gives $b=0.3161, V / Y=0.3623, K / Y=1.2928, Q=1.2803$, and $\omega=1.6551$.

${ }^{23}$ Laitner and Stolyarov (2003) argue that such peaks yield the best estimates of $Q$.
} 
TABLE 4

DECOMPOSITIONS OF $Q_{*}$ AND $\Delta_{*}$

\begin{tabular}{lccc}
\hline \multicolumn{4}{c}{ Decomposition of $Q_{*}(\theta, b)$} \\
\hline Benchmark Case & Standard Model & Longevity Effect & Blocking Effect \\
$Q_{*}(\theta, b)-1$ & $Q_{*}(0,0)-1$ & $Q_{*}(\theta, 0)-Q_{*}(0,0)$ & $Q_{*}(\theta, b)-Q_{*}(\theta, 0)$ \\
\hline 0.2471 & 0.1145 & 0.1234 & 0.0092 \\
\hline \multicolumn{4}{c}{ Decomposition of $\Delta_{*}$} \\
\hline Benchmark Case & Creative Destruction & Blocking Effect & Obsolescence \\
$\Delta_{*}$ & $\lambda(1-\theta)$ & $-b \lambda \theta G_{*}$ & $\gamma-n-g$ \\
\hline 0.150 & 0.0349 & -0.0098 & 0.1248 \\
\hline
\end{tabular}

5.2.3. Decompositions. We perform decompositions to quantify the contribution of derivative ideas to the value of intangible capital and to identify separate components of its depreciation rate.

Let $Q_{*}(\theta, b)$ denote the long-run equilibrium value of Tobin's average $Q$ given $(\theta, b)$, with all other parameters at benchmark levels. Table 4, panel 1, decomposes the value of intangible capital, $Q_{*}-1$, into three parts: (i) $Q_{*}(0,0)-1$ is the value of intangible capital in a standard model with no derivative inventions (i.e., $\theta=0$ ) and no blocking effect (i.e., $b=0)$; (ii) $Q_{*}(\theta$, $0)-Q_{*}(0,0)$ measures the longevity effect; and (iii) given $\theta, Q_{*}(\theta, b)-Q_{*}(\theta, 0)$ measures the blocking effect.

For our benchmark parameters (i.e., the first row of Table 2), the value of intangible capital is about 25 cents per dollar of tangible assets. In the standard model, intangible capital would be 11 cents per dollar of physical capital. In our framework, the longevity effect adds another 12 cents. The blocking effect accounts for an additional penny. In other words, the longevity effect doubles the value of intangible capital from the standard model, but, as the small magnitude of our estimates of $b$ suggests, the blocking effect is tiny.

Another way of thinking about the value of intangible capital is to consider how fast it depreciates. Recalling expression (32), we can write

$$
Q_{*}(\theta, b)=1+k_{*}^{\alpha-1} \cdot \frac{\vec{a}_{*} \cdot \vec{\mu}}{r_{*}+\Delta_{*}} .
$$

The bottom panel of Table 4 provides a decomposition of $\Delta_{*}$ that parallels the discussion in Section 3.2.

We can see that obsolescence, $\gamma-n-g$, at over $12 \%$ per year, is the major reason for depreciation of intangible capital. Obsolescence arises from technological change in other sectors. Such change raises the wage and also increases demand (by increasing the size of the remainder of the economy). These effects have opposite signs, but the first is much larger in the calculations-demand is so elastic that increases in marginal cost drastically reduce sales. The rate of creative destruction, in contrast, is just $3.5 \%$ per year. $^{24}$

5.2.4. Sensitivity analysis. Table 5 examines the effect of using different data for calibration by considering alternative values for $r_{*}$ and $g$ (Table 3 has already considered various values of $\lambda, \theta$, and $\left.\Delta_{*}\right)$.

The low values of $b$ in Table 3 show that our high benchmark depreciation rate for intangible capital, 0.15 , limits the latitude for other changes. Table 5 adjusts $\Delta_{*}$ downward when necessary to satisfy both (33) and $b \geq 0$.

${ }^{24}$ This rate of creative destruction exactly matches the industry average estimate in Caballero and Jaffe (2002, p. 131). 
TABLE 5

VALUE OF INTANGIBLE CAPITAL: BENCHMARK CASE AND EFFECTS OF CALIBRATING TO DIFFERENT DATA

\begin{tabular}{lcccccr}
\hline Parameters & $\Delta_{*}$ & $b$ & $V_{t} / Y_{t}$ & $K_{t} / Y_{t}$ & $Q_{t}$ & $\omega_{t}$ \\
\hline Benchmark case & $\mathbf{0 . 1 5 0 0}$ & $\mathbf{0 . 0 7 7 2}$ & $\mathbf{0 . 3 1 9 5}$ & $\mathbf{1 . 2 9 2 8}$ & $\mathbf{1 . 2 4 7 1}$ & $\mathbf{1 . 6 1 2 2}$ \\
$r_{\text {new }}=r+0.015$ & 0.1500 & 0.4071 & 0.2294 & 1.2928 & 1.1774 & 1.5222 \\
$r_{\text {new }}=r-0.015$ & 0.1240 & 0.0000 & 0.4724 & 1.2928 & 1.3654 & 1.7652 \\
$r_{\text {new }}=r-0.030$ & 0.0997 & 0.0000 & 0.6914 & 1.2928 & 1.5348 & 1.9842 \\
$g_{\text {new }}=g+0.005$ & 0.1500 & 0.1794 & 0.3608 & 1.2928 & 1.2924 & 1.5949 \\
$g_{\text {new }}=g-0.005$ & 0.1411 & 0.0000 & 0.2840 & 1.2928 & 1.2092 & 1.6413 \\
\hline
\end{tabular}

TABLE 6

COMPARATIVE STATIC ELASTICITIES (EVALUATED AT BENCHMARK PARAMETER VALUES)

\begin{tabular}{|c|c|c|c|c|c|c|c|}
\hline \multirow[b]{2}{*}{ Par. Change } & \multicolumn{7}{|c|}{ Outcome Variable } \\
\hline & $V_{t} / K_{t}$ & $\omega_{t}$ & $V_{t} / Y_{t}$ & $K_{t} / Y_{t}$ & $g$ & $r_{*}$ & $m_{*}$ \\
\hline$\theta$ & 0.92 & 0.15 & 0.89 & -0.03 & 0.00 & 0.00 & 0.03 \\
\hline$\lambda$ & -0.49 & -0.57 & -0.96 & -0.47 & 1.00 & 0.81 & 0.00 \\
\hline$z$ & -3.81 & -11.25 & -14.31 & -10.49 & 21.76 & 17.56 & 0.32 \\
\hline$\rho$ & 0.03 & -0.11 & -0.08 & -0.11 & 0.00 & 0.19 & 0.00 \\
\hline
\end{tabular}

Table 5 shows that the values of $r$ and $g$ used in calibration do have a noticeable bearing on the model's $(V / Y)_{*}$. Downward adjustments in $\Delta_{*}$ are frequently required in Table 5, and, in other cases, our estimate of $b$ rises appreciably (though never as far as 0.5 ).

5.3. Comparisons of Balanced-Growth Equilibria. This section examines the effect of plausible changes in our model's parameters on the market value of businesses. Tables 1 and 2 suggest that $\theta$ may have risen in recent decades, and it is natural to ask how the model predicts this should have affected stock-market valuations. The root cause for an increase in $\theta$ could have been a shift in technological change toward sectors with inherently high spillovers, such as semiconductors and computer hardware and software (Bessen and Maskin, 2006). Or, it could have been a change in patent policy to one affording protection to previously unpatentable areas or allowing more overlap in property rights (e.g., Hunt, 2001; Jaffe and Lerner, 2004). On the other hand, our measurements indicate a nearly coincident increase in $\lambda$. We can speculate that this, too, could have been a response to a policy change that favors patenting.

Table 6 presents comparative-static results. The first row increases $\theta$ while holding all other parameters constant. Table 2 suggests that $\theta$ may have risen as much as 0.1 from the 1970 s to the 1990s. Table 6 implies a resulting increase in $(V / Y)_{*}$ from 0.32 to 0.36 . In the same time period, $\lambda$ may have risen by 0.04 . The latter would have caused both $r_{*}$ and the rate of creative destruction to be higher. In the end, $(V / Y)_{*}$ would drop by $0.03-0.04$.

Table 2 suggests that $z$ may have fallen by 0.01 in recent decades. This fall in $z$ causes the aggregate productivity growth $g$ to fall from 0.02 to 0.016 . The fall in $g$, in turn, makes $r_{*}$ fall by about 0.02 . This will make $\omega_{*}$ higher. A fall in $z$, however, also lowers the average markup, which pushes $\omega_{*}$ down. In the end, the effect on $r_{*}$ is more powerful and $\omega_{*}$ rises from 1.61 to about 1.78 .

Finally, we a examine a change in $\rho$ that in our closed-economy model proxies for financial flows from abroad that may have significantly lowered the U.S. interest rate. A lower $\rho$ produces an analogous effect in the model, as $r_{*}$ falls one-to-one with $\rho$. As the interest rate falls, the model predicts a strong uptick in $\omega_{*}$. As both $V$ and $K$ rise, their ratio, $(V / K)_{*}$, is, however, almost unaffected.

This article focuses on equilibrium levels instead of changes. On the other hand, the roughly offsetting effects of $\theta$ and $\lambda$ on $(V / Y)_{*}$ calculated above suggest that understanding, and being 
TABLE 7

RELATIVE VALUES OF DERIVATIVE AND FUNDAMENTAL PATENTS

\begin{tabular}{lcccr}
\hline Relative Value & $b=0.0772$ & $b=0$ & $b=0.5$ & $b=1$ \\
\hline$\frac{\psi_{t}(1, N)}{\psi_{t}(0, N)}$ & 0.4982 & 0.5453 & 0.2584 & 0.0000 \\
$\frac{\psi_{t}(2, N)}{\psi_{t}(0, N)}$ & 0.4669 & 0.5085 & 0.2475 & 0.0000 \\
\hline
\end{tabular}

able separately to measure, components determining the aggregative rate of TFP growth is important for predicting changes in the market value of intangible capital.

5.4. Values of Individual Patents. Empirical papers note the heterogeneity of values of individual patents (Hall et al., 2005; Bertran, 2006; Cai, 2009). Our model generates a distribution of patent values, which this section briefly examines.

Let $\psi_{t}(d, N)$ be the market value of derivative patent $d$ at time $t$ in an industry with $N$ innovations, where $d=0$ is the active fundamental patent, $d=1$ the oldest active derivative, etc. With balanced growth, Section 3 shows

$$
\begin{aligned}
v_{t}(d+1, N) & =v_{0}(d+1,0) \cdot e^{(\gamma-n-g) \cdot t} \cdot z^{\frac{\eta}{1-\eta} \cdot N} \quad d \geq 0, \\
\psi_{t}(d, N) & = \begin{cases}v_{t}(1, N), & \text { if } d=0 . \\
(1-b)\left(v_{t}(d+1, N)-v_{t}(d, N-1)\right) & \text { if } d \geq 1 .\end{cases}
\end{aligned}
$$

The distribution of patent values then has two determinants. First, $N$ follows a Poisson process; so, the distribution of patent values spreads out over time, with higher values emerging in industries with higher TFP levels. Second, within each industry, ordering within the patent stream matters. Because $H=2$ in our calibrations, $v_{t}(d, N)=v_{t}(d+1, N)$ all $d \geq 2$. So,

$$
\frac{\psi_{t}(d, N)}{\psi_{t}(0, N)}=(1-b) \begin{cases}\frac{v_{0}(2,0)}{v_{0}(1,0)}-z^{-\frac{\eta}{1-\eta}} & \text { if } d=1 \\ \frac{v_{0}(2,0)}{v_{0}(1,0)}\left(1-z^{-\frac{\eta}{1-\eta}}\right) & \text { if } d \geq 2\end{cases}
$$

Table 7 presents relative values. Consider the case with $b=0.0772$. At its inception, a fundamental patent destroys the value of its predecessors and claims the entire industry profit for itself. When the first derivative arrives, it, in contrast, receives a fraction (i.e., $1-b$ ) of the incremental value that it brings to the pool. In Table 7, column 1, fundamental patents tend to be about twice as valuable, for the same $N$, as derivatives. Conceivably, developing fundamental inventions is also more expensive in practice. ${ }^{25}$ Nevertheless, our analysis points to substantially higher market valuations for fundamental inventions, though for reasons other than the blocking effect.

This article's primary focus is economy-wide growth and the aggregate value of intangible capital. However, Section 5.2 notes several interesting comparisons between our findings and, for instance, Hall et al. (2005). Furthermore, our model has many implications about individual patents that might form the basis for future work. For example, Table 7 shows that a patent's birth order can affect its relative net worth, and, in a regression explaining patent values, patents that cite one another should manifest a common component, reflecting their industry's $N$.

${ }^{25}$ In Young (1993), for example, some inventions evolve from learning by doing, whereas others require R\&D effort. 


\section{CONCLUSION}

This article expands the quality ladder growth model to incorporate both fundamental and derivative ideas. A derivative idea augments the usefulness of existing intangible capital; a fundamental idea is novel enough to stand alone.

We show that the new analytic framework provides a template for utilizing potentially rich, but otherwise difficult to interpret, U.S. patent data. The distinction between fundamental and derivative ideas turns out to be extremely important: $70-80 \%$ of patents seem to cover derivative inventions, and we show that recognition of this more than doubles the value of intangible capital that the model can explain for the U.S. economy.

Core allocations of rents for knowledge capital include those that prolong the economic life of existing patents, what we call the "longevity effect," and those that go further to allocate some, or all, of the incremental value of derivative patents to their progenitors. The "longevity effect" explains the doubling of value above. We find, however, little support in practice for more severe rent allocations away from derivative patents. This conclusion has potential consequences for private $\mathrm{R} \& \mathrm{D}$ incentives for both fundamental and derivative projects.

Our model has multiple industries, and our calibrations suggest that their outputs are quite good substitutes for one another. Thus, the predicted aggregate markup agrees with modest estimates in the existing literature. Our framework allows sector-specific time-varying markups, but our quantitative analysis points to only very small efficiency losses from cross-sectional markup asymmetry.

Each of our model's industries has an independent Poisson process governing its TFP growth. With good substitution options, the economy allocates extra resources to high TFP industries. We show that dynamic input reallocations of this nature can lift the aggregate rate of TFP growth $30-50 \%$ above the average rate of industry TFP growth.

The existing literature leads us to calibrate a high rate of depreciation for intangible capital. Our analysis attributes only about $20 \%$ of the total depreciation to creative destruction. The preponderance stems from "obsolescence," arising from TFP growth in competing industries.

\section{APPENDIX}

\section{A. Proofs.}

Proof of Lemma 1. For more compact notation, omit the time subscript throughout the proof. Using industry production function (3), the demands for capital and labor are

$$
R=\alpha \frac{x_{j}}{K_{j}}, \quad W=(1-\alpha) \frac{x_{j}}{L_{j}}
$$

Then, every industry must have the same capital-labor ratio $k=K_{j} / L_{j}=K / L$. Let $l_{j}=L_{j} / L$ denote the fraction of the total labor force employed in industry $j$. The demand curve for industry $j$ implies

$$
\begin{aligned}
\frac{Y}{x_{j}} & =\left[p_{j}\right]^{\frac{1}{1-\eta}}=\left[m_{j}\right]^{\frac{1}{1-\eta}} c^{\frac{1}{1-\eta}}\left[Z_{j}\right]^{-\frac{1}{1-\eta}} \\
\Longleftrightarrow & Y=x_{j}\left[m_{j}\right]^{\frac{1}{1-\eta}} c^{\frac{1}{1-\eta}}\left[Z_{j}\right]^{-\frac{1}{1-\eta}}=k^{\alpha} L \cdot l_{j} \cdot\left[m_{j}\right]^{\frac{1}{1-\eta}} c^{\frac{1}{1-\eta}}\left[Z_{j}\right]^{-\frac{\eta}{1-\eta}} \\
\Longleftrightarrow & l_{j}=\frac{Y}{K^{\alpha} L^{1-\alpha}}\left[m_{j}\right]^{-\frac{1}{1-\eta}} c^{-\frac{1}{1-\eta}}\left[Z_{j}\right]^{\frac{\eta}{1-\eta}} .
\end{aligned}
$$


Then, plugging (A.2) into the labor market clearing condition,

$$
\begin{aligned}
1 & =\int_{0}^{1} l_{j} d j=\frac{Y}{K^{\alpha} L^{1-\alpha} c^{\frac{1}{1-\eta}}} \int_{0}^{1}\left[m_{j}\right]^{-\frac{1}{1-\eta}}\left[Z_{j}\right]^{\frac{\eta}{1-\eta}} d j \\
& Z=\frac{Y}{K^{\alpha} L^{1-\alpha}}=\frac{c^{\frac{1}{1-\eta}}}{\int_{0}^{1}\left[m_{j}\right]^{-\frac{1}{1-\eta}}\left[Z_{j}\right]^{\frac{\eta}{1-\eta}} d j} .
\end{aligned}
$$

To get $c$ as a function of $Z_{j}$ and $m_{j}$, use (1):

$$
\begin{aligned}
Y & =\left(\int_{0}^{1} x_{j}^{\eta} d j\right)^{\frac{1}{\eta}}=\left(\int_{0}^{1}\left(Z_{j} k^{\alpha} l_{j} L\right)^{\eta} d j\right)^{\frac{1}{\eta}} \\
& =Y\left(\int_{0}^{1}\left(\left[m_{j}\right]^{-\frac{1}{1-\eta}} c^{-\frac{1}{1-\eta}}\left[Z_{j}\right]^{\frac{1}{1-\eta}}\right)^{\eta} d j\right)^{\frac{1}{\eta}} \quad \text { from (A.2) }
\end{aligned}
$$$$
\Longleftrightarrow c^{\frac{1}{1-\eta}}=\left(\int_{0}^{1}\left[Z_{j}\right]^{\frac{\eta}{1-\eta}}\left[m_{j}\right]^{-\frac{\eta}{1-\eta}} d j\right)^{1 / \eta} .
$$

This proves (7).

From (A.1),

$$
R K=\alpha X \quad \text { and } \quad W L=(1-\alpha) X, \quad \text { where } \quad X=\int_{0}^{1} x_{j} d j
$$

Substituting these into (4) yields

$$
c=\left(\frac{R}{\alpha}\right)^{\alpha}\left(\frac{W}{1-\alpha}\right)^{1-\alpha}=\frac{X}{K^{\alpha} L^{1-\alpha}} .
$$

Define

$$
m=\int_{0}^{1} l_{j} m_{j} d j
$$

Zero profit in the final goods sector implies

$$
\begin{aligned}
Y & =\int_{0}^{1} p_{j} x_{j} d j=\int_{0}^{1} \frac{c}{Z_{j}} m_{j} Z_{j} l_{j} k^{\alpha} L d j=c m K^{\alpha} L^{1-\alpha} \\
\Longleftrightarrow Y & =m X .
\end{aligned}
$$

Substituting $X=Y / m$ into (A.4) proves the first two conditions in (8). The third one follows from accounting.

It is left to prove (9). Expressions (A.5) and (6) imply

$$
m=\frac{Z}{c},
$$

and substituting from (7) and (A.3) into (A.6) completes the proof. 
Proof of Corollary to Lemma 1. If the initial distribution of markup states is $\vec{a}_{*}$, the markup state of an industry is independent of its number of arrivals $N_{j t}$. That is, for any $j$, $Z_{j t}$ and $m_{j t}$ are independent, with $m_{j t}$ being a realization of a random variable $\tilde{m}$ distributed according to $\left(\vec{m}, \vec{a}_{*}\right)$, and $Z_{j t}$ being a realization of a random variable

$$
\tilde{Z}_{t}=Z_{0} \cdot z^{N_{t}}
$$

where $Z_{0}$ has some distribution with a finite mean and $N_{t}$ has a Poisson distribution with parameter $\lambda t$.

We can use the law of large numbers (for a sample indexed by $j$ ) and the independence of $Z_{0}, N_{t}$, and $\tilde{m}$ to compute the integrals in (9) and (7) as follows:

$$
\begin{aligned}
m_{t} & =\frac{\int_{0}^{1}\left[Z_{j t}\right]^{\frac{\eta}{1-\eta}}\left[m_{j t}\right]^{-\frac{\eta}{1-\eta}} d j}{\int_{0}^{1}\left[Z_{j t}\right]^{\frac{\eta}{1-\eta}}\left[m_{j t}\right]^{-\frac{1}{1-\eta}} d j}=\frac{\mathbb{E}\left[\left[\tilde{Z}_{t}\right]^{\frac{\eta}{1-\eta}}[\tilde{m}]^{-\frac{\eta}{1-\eta}}\right]}{\mathbb{E}\left[\left[\tilde{Z}_{t}\right]^{\frac{\eta}{1-\eta}}[\tilde{m}]^{-\frac{1}{1-\eta}}\right]} \\
= & \frac{\mathbb{E}\left[\left[\tilde{Z}_{t}\right]^{\frac{\eta}{1-\eta}}\right] \cdot \mathbb{E}\left[[\tilde{m}]^{-\frac{\eta}{1-\eta}}\right]}{\mathbb{E}\left[\left[\tilde{Z}_{t}\right]^{\frac{\eta}{1-\eta}}\right] \cdot \mathbb{E}\left[[\tilde{m}]^{-\frac{1}{1-\eta}}\right]}=\frac{\vec{a}_{*} \cdot \vec{m}^{-\frac{\eta}{1-\eta}}}{\vec{a}_{*} \cdot \vec{m}^{-\frac{1}{1-\eta}}} .
\end{aligned}
$$

Similarly,

$$
\begin{aligned}
Z(t) & =\frac{\left(\mathbb{E}\left[\left[\tilde{Z}_{t}\right]^{\frac{\eta}{1-\eta}}[\tilde{m}]^{-\frac{\eta}{1-\eta}}\right]\right)^{1 / \eta}}{\mathbb{E}\left[\left[\tilde{Z}_{t}\right]^{\frac{\eta}{1-\eta}}[\tilde{m}]^{-\frac{1}{1-\eta}}\right]}=\frac{\left(\mathbb{E}\left[Z_{0}^{\frac{\eta}{1-\eta}}\right]\right)^{1 / \eta} \cdot\left(\mathbb{E}\left[z^{\frac{\eta}{1-\eta} N_{t}}\right]\right)^{1 / \eta} \cdot\left(\mathbb{E}\left[\tilde{m}^{-\frac{\eta}{1-\eta}}\right]\right)^{1 / \eta}}{\mathbb{E}\left[Z_{0}^{\frac{\eta}{1-\eta}}\right] \cdot \mathbb{E}\left[z^{\frac{\eta}{1-\eta} N_{t}}\right] \cdot \mathbb{E}\left[\tilde{m}^{-\frac{1}{1-\eta}}\right]} \\
& =\left(\mathbb{E}\left[Z_{0}^{\frac{\eta}{1-\eta}}\right]\right)^{\frac{1-\eta}{\eta}} \cdot\left(\mathbb{E}\left[z^{\frac{\eta}{1-\eta}} N_{t}\right]\right)^{\frac{1-\eta}{\eta}} \cdot \frac{\left(\mathbb{E}\left[\tilde{m}^{-\frac{\eta}{1-\eta}}\right]\right)^{1 / \eta}}{\mathbb{E}\left[\tilde{m}^{-\frac{1}{1-\eta}}\right]} .
\end{aligned}
$$

The first term of the above expression is $\bar{Z}_{0}$, the second term equals

$$
\left(\mathbb{E}\left[z^{\frac{\eta}{1-\eta} N_{t}}\right]\right)^{\frac{1-\eta}{\eta}}=\left[e^{-\lambda t} \sum_{N=0}^{\infty} \frac{\left(\lambda z^{\frac{\eta}{1-\eta}} t\right)^{N}}{N !}\right]^{\frac{1-\eta}{\eta}}=\exp \left(\gamma \frac{1-\eta}{\eta} t\right)
$$

and the third term is $\bar{m}$.

Proof of Proposition 1. This is a special case of Proposition 2 for $H=1$ and $m_{*}=1 / \eta$.

Proof of Lemma 2. First, establish (24). The profit of the industry leader equals

$$
\begin{aligned}
\pi_{j t} & =\left(p_{j t}-\frac{c_{t}}{Z_{j t}}\right) x_{j t}=\left(m_{j t}-1\right) c_{t} \frac{x_{j t}}{Z_{j t}}=\left(m_{j t}-1\right) c_{t} k_{t}^{\alpha} L_{t} \cdot l_{j t} \\
& =\left(m_{j t}-1\right) c_{t} K_{t}^{\alpha} L_{t}^{1-\alpha} \frac{Y_{t}}{K_{t}^{\alpha} L_{t}^{1-\alpha}}\left[m_{j t}\right]^{-\frac{1}{1-\eta}} c_{t}^{-\frac{1}{1-\eta}}\left[Z_{j t}\right]^{\frac{\eta}{1-\eta}} \quad \text { from (A.2) } \\
& =\frac{m_{j t}-1}{m_{j t}} Y_{t}\left(\frac{m_{t}}{m_{j t}}\right)^{\frac{\eta}{1-\eta}}\left(\frac{Z_{j t}}{Z_{t}}\right)^{\frac{\eta}{1-\eta}}=\left(m_{j t}^{-\frac{\eta}{1-\eta}}-m_{j t}^{-\frac{1}{1-\eta}}\right) Y_{t} \cdot m_{t}^{\frac{\eta}{1-\eta}}\left(\frac{Z_{j t}}{Z_{t}}\right)^{\frac{\eta}{1-\eta}} \quad \text { from (A.6). }
\end{aligned}
$$

Next, substitute 


$$
Z_{j t}=Z_{j 0} e^{N_{j t}}, m_{t}=m_{*}
$$

and

$$
Z_{t}^{\frac{\eta}{1-\eta}}=\mathbb{E}\left[Z_{j 0}^{\frac{\eta}{1-\eta}}\right] \bar{m}^{\frac{\eta}{1-\eta}} e^{\gamma t}
$$

from the Corollary to Lemma 1 into the expression for $\pi_{j t}$ and take the conditional expectation:

$$
\begin{aligned}
\pi_{t}(h, N) & =\left(m_{h}^{-\frac{\eta}{1-\eta}}-m_{h}^{-\frac{1}{1-\eta}}\right) m_{*}^{\frac{\eta}{1-\eta}} \cdot Y_{t} \cdot Z_{t}^{-\frac{\eta}{1-\eta}} \cdot \mathbb{E}\left[Z_{j 0}^{\frac{\eta}{1-\eta}}\right] z^{N \frac{\eta}{1-\eta}} \\
& =\left(m_{h}^{-\frac{\eta}{1-\eta}}-m_{h}^{-\frac{1}{1-\eta}}\right) \cdot\left(\frac{m_{*}}{\bar{m}}\right)^{\frac{\eta}{1-\eta}} \cdot Y_{t} \cdot e^{-\gamma t} \cdot z^{N \frac{\eta}{1-\eta}} \quad \text { from (11)-(13) } \\
& =\frac{m_{h}^{-\frac{\eta}{1-\eta}}-m_{h}^{-\frac{1}{1-\eta}}}{\vec{a}_{*} \cdot \vec{m}^{-\frac{\eta}{1-\eta}}} \cdot Y_{t} \cdot e^{-\gamma t} \cdot z^{N \frac{\eta}{1-\eta}}
\end{aligned}
$$

This proves (24).

From (24),

$$
\pi_{t}(h, N)=\pi_{t}(h, 0) \cdot z^{N \frac{\eta}{1-\eta}}, \text { for all }(h, N) .
$$

Then, induction on $h$ in (23) shows that

$$
v_{t}(h, N)=v_{t}(h, 0) \cdot z^{N \frac{\eta}{1-\eta}}, \quad \text { for all } \quad(h, N) .
$$

Finally, setting $N=0$ in (23) and differentiating with respect to $t$ proves (27).

Proof of Proposition 2. First, show that

$$
\sum_{h=1}^{H} a_{* h} \cdot \pi_{t}(h, 0)=\Pi_{t} \cdot e^{-\gamma t}
$$

Using (24) in Lemma 2, we can write

$$
\sum_{h=1}^{H} a_{* h} \cdot \pi_{t}(h, 0)=\left(\vec{a}_{*} \cdot \vec{\mu}\right) \cdot Y_{t} \cdot e^{-\gamma t}=\left(1-\frac{1}{m_{*}}\right) \cdot Y_{t} \cdot e^{-\gamma t}=\Pi_{t} \cdot e^{-\gamma t} .
$$

Next, differentiate the expression (28) for aggregate patent value and use (27) from Lemma 2 and (28) to write

$$
\begin{aligned}
\dot{V}_{t} & =\gamma V_{t}+e^{\gamma t} \sum_{h=1}^{H} a_{* h} \cdot \dot{v}_{t}(h, 0) \\
& =\gamma V_{t}+\left(\lambda+r_{t}\right) V_{t}-\lambda \theta(1-b) V_{t}-\lambda \theta b z^{\frac{\eta}{1-\eta}} \cdot \frac{\sum_{h=1}^{H} a_{* h} \cdot v_{t}(h \oplus 1,0)}{\sum_{h=1}^{H} a_{* h} \cdot v_{t}(h, 0)} V_{t}-\Pi_{t} .
\end{aligned}
$$


Proof of Proposition 3. The proof will use the following two facts:

Fact 1. Conditional on $n$ Poisson events within the last $T$ periods, the joint distribution of the arrival times $t_{1}<\cdots<t_{n}$ is uniform on [0,T] (Van Mieghem, 2006, p. 126). In other words, conditional on exactly $n$ Poisson arrivals, arrival times are distributed in the same way as the set of $n$ order statistics for the uniform distribution $U[0, T]$. The marginal distribution for each $t_{h}$ is a beta distribution with parameters $h$ and $n-h+1$ (Hogg and Craig (1995), p. 201), and its mean is

$$
\mathbb{E} t_{h}=\frac{h}{n+1} T
$$

Fact 2.

$$
\Sigma_{N} \triangleq \sum_{h=0}^{N} h \theta^{h}=\frac{\theta}{(1-\theta)^{2}}\left(1-\theta^{N+1}\right)-\frac{N+1}{1-\theta} \theta^{N+1}, \quad \text { for all } \quad N \geq 0
$$

Let

$$
P_{n}=\frac{e^{-\lambda T}(\lambda T)^{n}}{n !}
$$

be the probability of $n$ Poisson events within the last $T$ periods.

Consider all industries where the active patent makes at least one citation. This set consists of industries where the current patent is a derivative idea and that have experienced at least one Poisson event within the last $T$ periods. The measure of such industries is $\sum_{n=1}^{\infty} \theta P_{n}$. An active patent in an industry that experienced $n$ prior arrivals can make between 1 and $n$ citations. When a patent makes $h \geq 1$ citations, (A.7) implies that the corresponding average minimum citation lag is

$$
s(n)=\frac{T}{n+1},
$$

and the average maximum citation lag is

$$
S_{h}(n)=\frac{h T}{n+1}
$$

Compute the average maximum citation lag first. The probability to make $h$ citations conditional on making at least one equals

$$
\mathbb{P}(h \mid h \geq 1)=\frac{\mathbb{P}(h \cap h \geq 1)}{\mathbb{P}(h \geq 1)}=\left\{\begin{array}{ll}
(1-\theta) \theta^{h-1} & 1 \leq h \leq n-1 \\
\theta^{n-1} & h=n
\end{array} .\right.
$$

The mean maximum citation lag in an industry with $n$ arrivals is

$$
\begin{aligned}
\mathbb{E}\left(S_{h}(n) \mid n\right) & =\frac{T}{n+1}\left(\sum_{h=1}^{n-1} h \theta^{h-1}(1-\theta)+n \theta^{n-1}\right)=\frac{T}{n+1}\left(\sum_{h=0}^{n-2}(h+1) \theta^{h}(1-\theta)+n \theta^{n-1}\right) \\
& =\frac{T}{n+1}\left((1-\theta) \Sigma_{n-2}+(1-\theta) \sum_{h=0}^{n-2} \theta^{h}+n \theta^{n-1}\right)
\end{aligned}
$$




$$
\begin{aligned}
& =\frac{T}{n+1}\left(\frac{\theta}{1-\theta}\left(1-\theta^{n-1}\right)-(n-1) \theta^{n-1}+\left(1-\theta^{n-1}\right)+n \theta^{n-1}\right) \\
& =\frac{T}{n+1}\left(\frac{1}{1-\theta}-\frac{\theta^{n}}{1-\theta}\right) .
\end{aligned}
$$

The mean maximum citation lag across industries that experience current arrivals and make at least one citation equals

$$
\bar{S}=\frac{\sum_{n=1}^{\infty} \theta P_{n} \cdot \mathbb{E}\left(S_{h}(n) \mid n\right)}{\sum_{n=1}^{\infty} \theta P_{n}} .
$$

To compute the numerator of this ratio, we need to evaluate two sums:

$$
\sum_{n=1}^{\infty} \frac{P_{n}}{n+1}=\frac{1}{\lambda T} e^{-\lambda T} \sum_{n=1}^{\infty} \frac{(\lambda T)^{n+1}}{(n+1) !}=\frac{1}{\lambda T} e^{-\lambda T} \sum_{n=2}^{\infty} \frac{(\lambda T)^{n}}{n !}=\frac{1}{\lambda T} e^{-\lambda T}\left(e^{\lambda T}-1-\lambda T\right),
$$

and

$$
\sum_{n=1}^{\infty} \frac{P_{n} \theta^{n}}{n+1}=\frac{1}{\lambda T \theta} e^{-\lambda T} \sum_{n=1}^{\infty} \frac{(\lambda T \theta)^{n+1}}{(n+1) !}=\frac{1}{\lambda T \theta} e^{-\lambda T} \sum_{n=2}^{\infty} \frac{(\lambda T \theta)^{n}}{n !}=\frac{1}{\lambda T \theta} e^{-\lambda T}\left(e^{\lambda T \theta}-1-\lambda T \theta\right) .
$$

Using these expressions, the mean maximum citation lag is

$$
\begin{aligned}
\bar{S} & =\frac{\frac{T}{1-\theta} \sum_{n=1}^{\infty} \frac{P_{n}}{n+1}-\frac{T}{(1-\theta)} \sum_{n=1}^{\infty} \frac{P_{n} \theta^{n}}{n+1}}{1-P_{0}} \\
& =e^{-\lambda T \frac{\frac{1}{\lambda(1-\theta)}\left(e^{\lambda T}-1-\lambda T\right)-\frac{1}{\lambda \theta(1-\theta)}\left(e^{\lambda T \theta}-1-\lambda T \theta\right)}{1-P_{0}}} \\
& =\frac{1}{\lambda(1-\theta)}\left(1-\frac{\lambda T}{e^{\lambda T}-1}-\frac{e^{\lambda T \theta}-1-\lambda T \theta}{\theta\left(e^{\lambda T}-1\right)}\right) .
\end{aligned}
$$

Similarly, the mean minimum citation lag is ${ }^{26}$

$$
\bar{s}=\frac{\sum_{n=1}^{\infty} \theta P_{n} s(n)}{\sum_{n=1}^{\infty} \theta P_{n}}=\frac{1}{1-P_{0}} \sum_{n=1}^{\infty} \frac{P_{n}}{n+1}=\frac{1}{\lambda}\left(1-\frac{\lambda T}{e^{\lambda T}-1}\right) .
$$

${ }^{26}$ Note that

$$
\lim _{\theta \rightarrow 0} \bar{S}=\bar{s},
$$

and

$$
\lim _{\theta \rightarrow 1} \bar{S}=\frac{1}{\lambda} \frac{1}{e^{\lambda T}-1} \frac{\partial}{\partial \theta}\left[\frac{e^{\lambda T \theta}-1-\lambda T \theta}{\theta}\right]_{\theta=1}=T-\bar{s}
$$




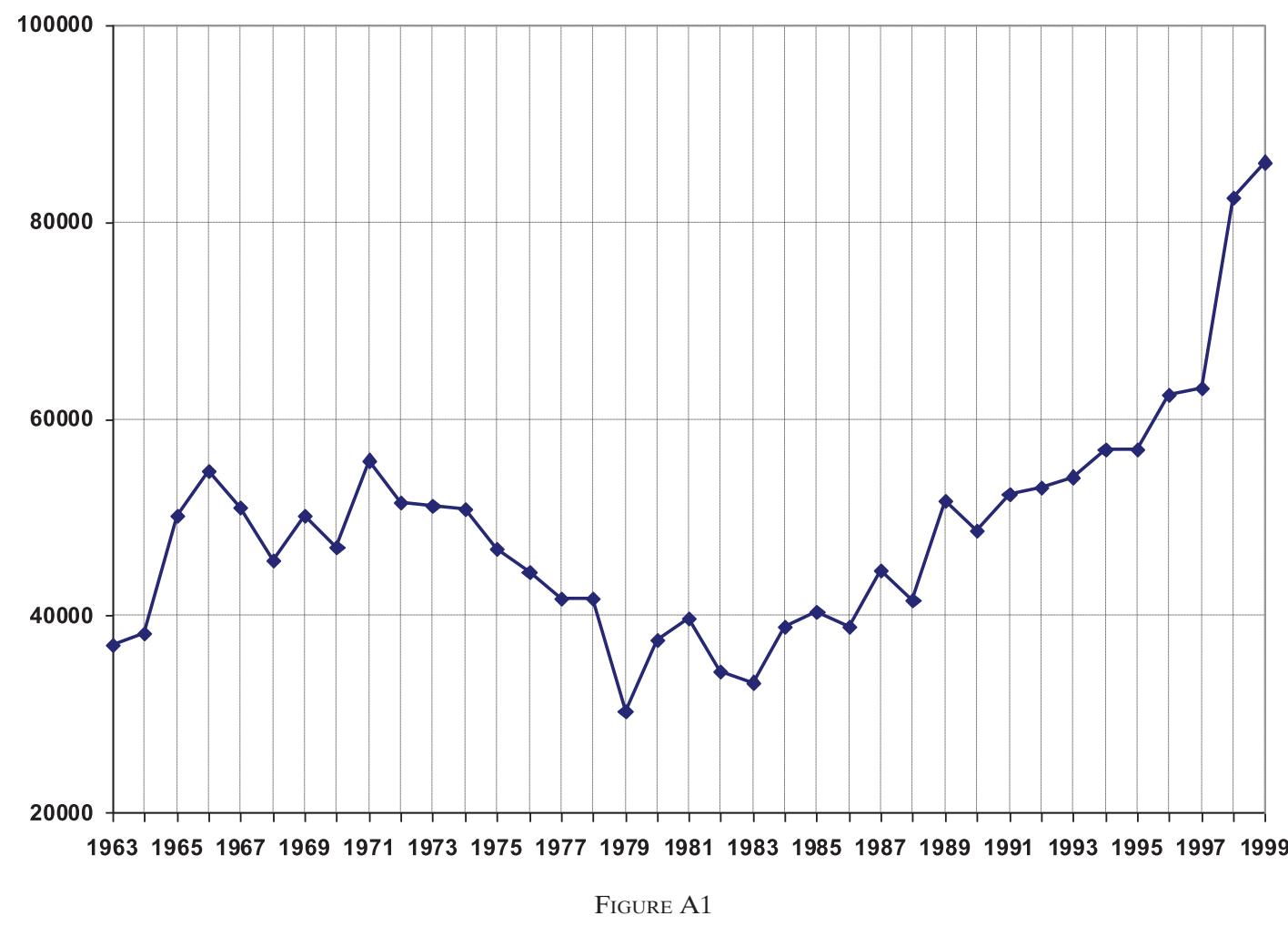

PATENT GRANTS TO DOMESTIC INVENTORS OR ASSIGNEES, 1963-1999

\section{B. Alternative Empirical Procedures: Counts Versus Lags}

This section explains why we think that our procedure based upon citation lags is potentially more reliable than methods based upon counts of patent grants or citations.

Consider the evidence on patent counts. Figure A1 shows yearly patent grants in our restricted sample. The variance in Figure A1 is enormous, and the data's apparent pattern depends heavily on the time frame of analysis. For example, although the rise in grants from 1979-1999 is almost $200 \%$, the overall pattern would appear cyclic without data from 1998-1999. The longer term data in Griliches (1990, Figure 2) show only slight evidence of growth in domestic patent applications in 1950-1990. Even if there is a trend in Figure A1, it may have little bearing on our model: In different eras, political sentiment toward antitrust enforcement may shift, affecting the desirability of patenting in practice (Schmookler, 1966), or the nature of improvements (e.g., process or product) or mix of industries enjoying rapid progress may change (Mansfield et al., 1981; Levin et al., 1987). Such factors, fortunately, need not affect the minimum and maximum citation lags used in our calibration.

In addition, the mapping between the patent counts data and the model requires an additional parameter. Figure A1 shows average patent grants to U.S. inventors of roughly 50,000 per year in 1963-1995. If there were 1,000 intermediate-good industries, we could calibrate our Poisson arrival rate to $\lambda=50.00$. If there were 100,000 industries, on the other hand, the calibration would be $\lambda=0.50$. Patent counts determine $\lambda$ only if one can specify the correspondence between industries in the data and the model, a mapping not otherwise needed in our analysis.

Turning to citation counts, Figure A2 shows the average number of citations made to patents within either the same three-digit patent class (USPTO definition) or a two-digit technological category (Hall et al., 2001). (To minimize visual biases, Figure A2 includes only citations less than 13 years old.) The figure shows a tripling of citation counts in 1975-1999. It seems likely that improvements in electronic search procedures provide much of the explanation (Hall 


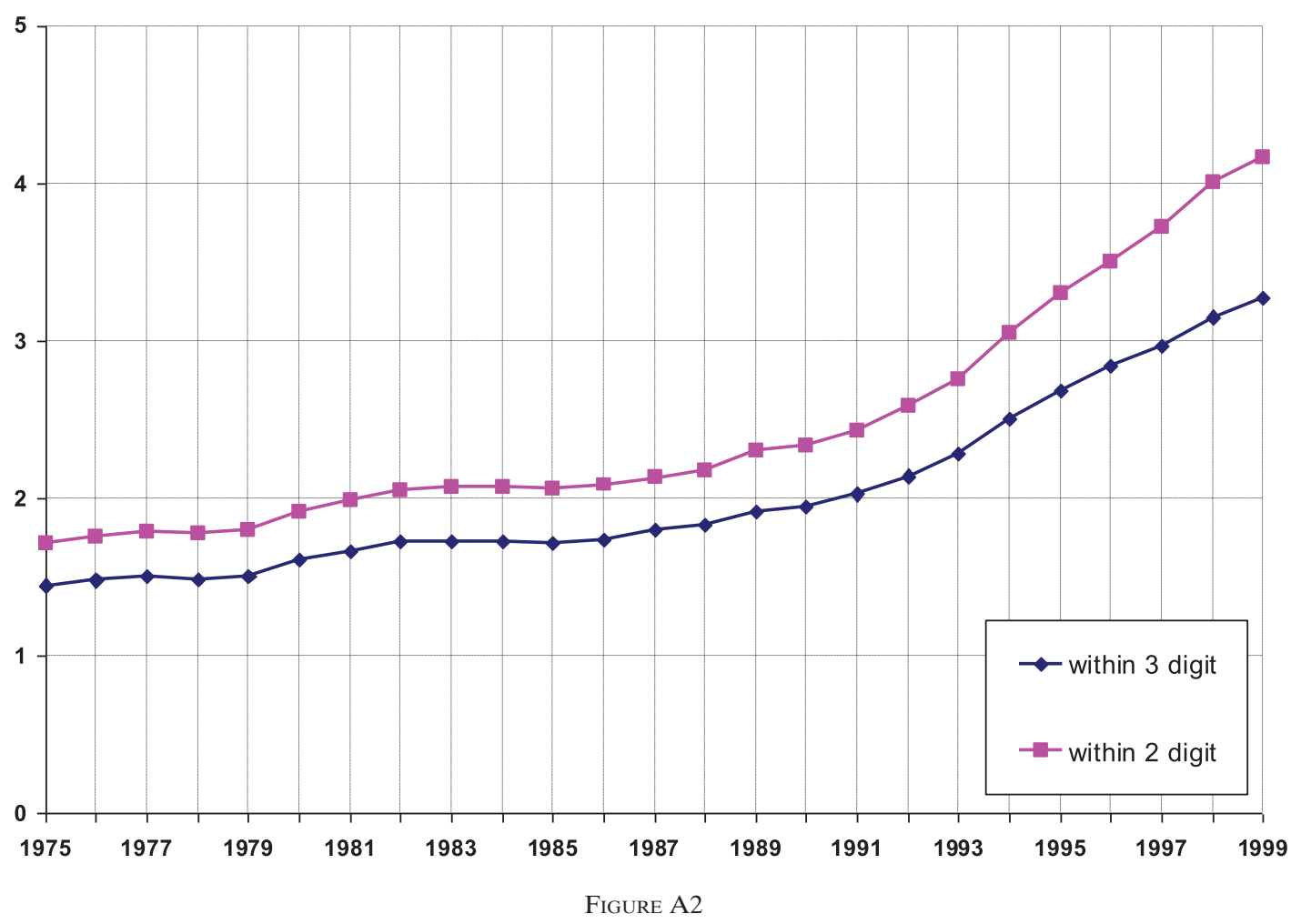

NUMBER OF CITATIONS MADE TO PATENTS WITHIN THE SAME THREE-DIGIT CLASS OR A TWO-DIGIT CATEGORY, 1975-1999

et al., 2001). That development complicates one's interpretation of citation numbers, because a change in patent search technology introduces a time-varying bias. Calibrations based on citation lags, by contrast, are likely to be more robust. For example, if older derivative patents always cited their parent fundamental patent and the most recent related derivative (while perhaps sometimes neglecting intervening derivative patents), neither omissions in early years nor changes in omissions over time need affect measurements based on minimum and maximum lags.

Patent clusters may introduce further complications. Inventions often have several dimensions of novelty, and inventors may seek to patent them separately. Thus, the single "invention" in our model that raises technology level $Z_{j t}$ to $z \cdot Z_{j t}$ may sometimes generate a cluster of patents in practice. A stream consisting of a fundamental patent and three derivatives should, if there are no clusters, generate six citations. If, however, every innovation (fundamental and derivative) consists of a cluster of two concurrent patents, the total number of citations climbs to $24-$ even if concurrent patents do not cite one another. With clusters of three, total citations rise to 54. If growing sophistication of technologies over time stimulates larger clusters of patents, this may contribute to a rise in both patent grants (Figure A1) and citation counts in Figure A2. On the other hand, the existence of clusters does not necessarily shorten, or lengthen, the minimum or maximum citation lags on which this article's calibrations depend.

Table A1 provides additional evidence. If each invention generates a single patent, we would expect that among all patents that make $h$ citations in the window $\left[t-T, t\right.$ ), a fraction $[1 / T]^{h-1}$ would have all $h$ citations occurring with the same yearly lag. If, on the other hand, cluster patenting is significant, we should see disproportionately many citations with coincident lags. Table A1, column 1, presents coincidence rates from the data. We use citations with lags of less than 13 years, and we drop citations within the calendar year of the citing patent-leaving $T=$ 12. Column 2 calculates $[1 / T]^{h-1}$. Table A1 shows that coincidence rates in the data are indeed many times higher than the model predicts. The discrepancy expands with $h$. The latter is not 
TABLE A1

FREQUENCY OF COINCIDENT CITATION LAG LENGTHS

\begin{tabular}{lcc}
\hline & \multicolumn{2}{c}{ Fraction of Patents with Coincident Lags for All } \\
Citations
\end{tabular}

unexpected: the existence not only of clusters of two patents for the same invention but also of three, four, five, or more in some cases can make the empirical probabilities exceed random chance by a wide margin if $h$ is large.

Our model predicts the number of citations a time- $t$ patent makes on $[t-T, t)$. Data on numbers of citations per patent show puzzlingly large counts: Figure A2 shows citation counts (within the same three-digit industry) per new patent rising from about 1.5 to 4.5; with $T=12.5$ and parameter values from columns 3 and 4 of Table 1 , our model predicts counts of 1.1252 in 1975, 1.0614 in 1980, and 1.6146 in 1999. We conjecture that the high citation numbers in Figure A2 reflect, at least in part, cluster patenting. However, a more detailed investigation of the relationship between citation counts and clustering remains a topic for future research.

In general, the changes over time displayed in Table 1 are very small relative to the enormous movements evident in Figures A1 and A2. We have argued that the latter movements may well reflect exogenous factors and that citation lags can provide more dependable estimates of $\lambda$ and $\theta$.

\section{REFERENCES}

Atkeson, A., And P. J. Kehoe, "Modeling and Measuring Organization Capital," Journal of Political Economy 113(3) (2005), 1026-53.

Barro, R. J., And X. SAla-I-Martin, Economic Growth (Cambridge, MA: MIT Press, 1999).

BASU, S., AND J. G. Fernald, "Returns to Scale in US Production: Estimates and Implications," Journal of Political Economy 105(2) (1997), 249-83.

Belenzon, S., "Knowledge Flow and Sequential Innovation: Implications for Technology Diffusion, R\&D and Market Value," University of Oxford Department of Economics Discussion Paper series No. 259, March 2006.

Bertran, F. L., "Pricing Patents through Citations," Mimeo, Univeristy of Iowa, 2006.

Bessen, J., AND E. MAskin, "Sequential Innovation, Patents, and Imitation,” Institute for Advanced Study, School of Social Science, Economics Working Papers No. 0025, 2006.

Caballero, R. J., And A. B. JAFFe, "How High Are the Giants' Shoulders? An Empirical Assessment of Knowledge Spillovers and Creative Destruction in a Model of Economic Growth," in A. B. Jaffe and M. Trajtenberg, eds., Patents, Citations and Innovations: A Window into the Knowledge Economy (Cambridge, MA: MIT Press, 2002).

CAI, A. J., "Knowledge Spillover and Firm Size Heterogeneity," Job Market Paper, University of British Columbia, 2009.

Chang, H. F., "Patent Scope, Antitrust Policy, and Cumulative Innovation," The Rand Journal of Economics 26(1) (1995), 34-57.

Chu, A., "Effects of Blocking Patents on R\&D: A Quantitative DGE Analysis," Journal of Economic Growth 14 (2009), 55-78.

Cooley, T. F., and E. C. Prescott, "Economic Growth and Business Cycles,” in T. F. Cooley, ed., Frontiers of Business Cycle Research (Princeton, NJ: Princeton University Press, 1995).

Corrado, C., C. Hulten, and D. Sichel, "Intangible Capital and Economic Growth," Finance and Economics Discussion Series, Divisions of Research \& Statistics and Monetary Affairs, Federal Reserve Board, Washington, DC, 2006-24.

Green, J. R., And S. Scotchmer, "On the Division of Profit in Sequential Innovation," The RAND Journal of Economics 26(1) (1995), 20-33. 
Griliches, Z., "Patent Statistics as Economic Indicators: A Survey," Journal of Economic Literature 28(4) (1990), 1661-707.

Grossman, G. M., And E. Helpman, "Quality Ladders in the Theory of Growth," Review of Economic Studies 58(1) (1991), 43-61.

Hall, B. H., A. B. Jaffe, and M. Trajtenberg, "The NBER Patent Citations Data File: Lessons, Insights, and Methodological Tools," NBER Working Paper No. w8498, October 2001.

—, AND —_ "Market Value and Patent Citations," RAND Journal of Economics, 36(1) (2005), 16-38.

Harhoff, D., F. Narin, F. M. Scherer, and K. Vopel, "Citation Frequency and the Value of Patented Inventions," The Review of Economics and Statistics 81(3) (1999), 511-5.

Hunt, R. M., "You Can Patent That? Are Patents on Computer Programs and Business Methods Good for the New Economy?" Federal Reserve Bank of Philadelphia Business Review Q1 (2001), 5-15.

J AFFE, A. B., AND J. LeRner, Innovation and Its Discontents: How Our Broken Patent System Is Endangering Innovation and Progress, and What to Do About It (Princeton, NJ: Princeton University Press, 2004).

, M. Trajtenberg, and M. S. Fogarty, "The Meaning of Patent Citations: Report on the NBER/Case Western Reserve Survey of Patentees, ” in A. B. Jaffe and M. Trajtenberg, eds., Patents, Citations, and Innovations (Cambridge, MA: MIT Press, 2002).

,-- , AND R. HENDERSON, "Georgraphic Localization of Knowledge Spillovers as Evidenced by Patent Citations," The Quarterly Journal of Economics 108(3) (1993), 577-98.

Jones, C. I., AND J. C. Williams, "Too Much of a Good Thing? The Economics of Investment in R\&D," Journal of Economic Growth 5(1) (2000), 65-85.

Kortum, S., "Equilibrium R\&D and the Patent-R\&D Ratio: U.S. Evidence," The American Economic Review 83(2) (1993), 450-7.

, "Research, Patenting and Technological Change," Econometrica 65(6) (1997), 1389-419.

Laitner, J. P., And D. Stolyarov, "Technological Change and the Stock Market," American Economic Review 93(4) (2003), 1240-67.

— AND _ "Aggregate Returns to Scale and Embodied Technical Change: Theory and Measurement," Journal of Monetary Economics 51(1) (2004), 191-233.

Lanjouw, J. O., and M. Schankerman, "Patent Quality and Research Productivity: Measuring Innovation with Multiple Indicators," The Economic Journal 114(495) (2004), 441-65.

Levin, R. C., A. K. Klevorick, R. R. Nelson, S. G. Winter, R. Gilbert, and Z. Griliches, “Appropriating the Returns from Industrial Research and Development," Brookings Papers on Economic Activity 1987(3), Special Issue on Microeconomics (1987), 783-831.

Matutes, C., Regibeau, P., and K. Rockett, "Optimal Patent Design and the Diffusion of Innovations," RAND Journal of Economics 27(1) (1996), 60-83.

McGrattan, E., and E. C. Prescott, "Is the Stock Market Overvalued?" Federal Reserve Bank of Minneapolis Quarterly Review 24(4) (Fall 2000), 20-40.

- AND - "Expensed and Sweat Equity and the Macroeconomy," Federal Reserve Bank of Minneapolis Research Department Working Paper 636, November 2005.

NAdiRi, M. I., AND I. R. Prucha, "Estimation of the Depreciation Rate of Physical and R\&D Capital in the U.S. Total Manufacturing Sector," Economic Inquiry 34 (1996), 43-56.

NGai, R., And R. Samaniego, "Accounting for Research and Productivity Growth Across Industries," London School of Economics CEPR Discussion Paper DP 6408, March 2009.

Norrbin, S., "The Relationship between Price and Marginal Cost in U.S. Industry: A Contradiction," Journal of Political Economy 101 (1993), 1149-64.

Pakes, A., "Patents as Options: Some Estimates of the Value of Holding European Patent Stocks," Econometrica 54(4) (1986), 755-84.

- And M. Scherkerman, "The Rate of Obsolescence of Patents, Research Gestation Lags, and the Private Rate of Return to Research Resources," in Z. Griliches, ed., $R \& D F$, Patents, and Productivity (Chicago: The University of Chicago Press, 1984).

Rotemberg, J. J., And M. Woodford, "Dynamic General Equilibrium Models with Imperfectly Competitive Product Markets," in T. F. Cooley, ed., Frontiers of Business Cycle Research (Princeton, NJ: Princeton University Press, 1995).

Schankerman, M., And A. Pakes, "Estimates of the Value of Patent Rights in European Countries During the Post-1950 Period," Economic Journal 96(384) (1986), 1052-76.

SCHMOOKLeR, J., Invention and Economic Growth (Cambridge, MA: Harvard University Press, 1966).

Scotchmer, S., "Standing on the Shoulders of Giants: Cumulative Research and the Patent Law," The Journal of Economic Perspectives 5(1) (1991), 29-41.

_ , "Protecting Early Innovators: Should Second-Generation Products Be Patentable?" The Rand Journal of Economics 27 (1996), 322-31.

Segerstrom, P. S., "Innovation, Imitation, and Economic Growth," The Journal of Political Economy 99(4) (1991), 807-27. 
Thompson, P., And M. Fox-Kean, "Patent Citations and the Geography of Knowledge Spillovers: A Reassessment," American Economic Review 95(1) (2005), 450-60.

Trajtenberg, M., R. Henderson, and A. B. Jaffe, "University versus Corporate Patents: A Window on the Basicness of Invention," in A. B. Jaffe and M. Trajtenberg, eds., Patents, Citations and Innovations: A Window into the Knowledge Economy (Cambridge, MA: MIT Press, 2002).

Van Mieghem, J. A., Performance Analysis of Communications Networks and Systems (Cambridge, UK: Cambridge University Press, 2006).

Young, Alwyn., "Invention and Bounded Learning by Doing," Journal of Political Economy 101(3) (1993), 443-72. 